\title{
Effect of Low Temperature Cultivation on the Phytochemical Profile and Bioactivity of Arctic Plants: A Case of Dracocephalum palmatum
}

\author{
Daniil N. Olennikov ${ }^{1,2, *}$ (D), Nadezhda K. Chirikova ${ }^{2}$, Nina I. Kashchenko ${ }^{1}$ (D), \\ Tat'yana G. Gornostai ${ }^{3}$, Inessa Yu. Selyutina ${ }^{4}$ and Ifrat N. Zilfikarov ${ }^{5}$ \\ 1 Institute of General and Experimental Biology, Siberian Division, Russian Academy of Science, \\ Sakh'yanovoy Street 6, 670047 Ulan-Ude, Russia; ninkk@mail.ru \\ 2 Department of Biochemistry and Biotechnology, North-Eastern Federal University, 58 Belinsky Street, \\ 677027 Yakutsk, Russia; hofnung@mail.ru \\ 3 Siberian Institute of Plant Physiology and Biochemistry, Siberian Division, Russian Academy of Science, \\ Lermontova Street 132, 664033 Irkutsk, Russia; t.g.gornostay@yandex.ru \\ 4 Central Siberian Botanical Garden, Siberian Division, Russian Academy of Science, \\ Zolotodolinskaya Street 1, 630090 Novosibirsk, Russia; selyutina.inessa@mail.ru \\ 5 All-Russian Institute of Medical and Aromatic Plants, Greena Street 7/1, 117216 Moscow, Russia; \\ zilfikarovin@mail.ru \\ * Correspondence: olennikovdn@mail.ru; Tel.: +7-902-160-0627
}

Received: 2 October 2017; Accepted: 28 November 2017; Published: 30 November 2017

\begin{abstract}
The influence of climatic factors, e.g., low temperature, on the phytochemical composition and bioactivity of the arctic plant Dracocephalum palmatum Steph. ax Willd. (palmate dragonhead), a traditional food and medical herb of Northern Siberia, was investigated. D. palmatum seedlings were grown in a greenhouse experiment at normal $\left(20^{\circ} \mathrm{C}, \mathrm{NT}\right)$ and low $\left(1^{\circ} \mathrm{C}, \mathrm{LT}\right)$ temperature levels and five groups of components that were lipophilic and hydrophilic in nature were characterized. The analyses indicated that D. palmatum under NT demonstrates high content of photosynthetic pigments, specific fatty acid (FA) profile with domination of saturated FA (53.3\%) and the essential oil with trans-pinocamphone as a main component (37.9\%). Phenolic compounds were identified using a combination of high performance liquid chromatography with diode array detection and electrospray ionization mass-spectrometric detection (HPLC-DAD-ESI-MS) techniques, as well as free carbohydrates and water soluble polysaccharides. For the first time, it was established that the cold acclimation of $D$. palmatum seedlings resulted in various changes in physiological and biochemical parameters such as membrane permeability, photosynthetic potential, membrane fluidity, leaf surface secretory function, reactive oxygen species-antioxidant balance, osmoregulator content and cell wall polymers. In brief, results showed that the adaptive strategy of $D$. palmatum under LT was realized on the accumulation of membrane or surface components with more fluid properties (unsaturated FA and essential oils), antioxidants (phenolic compounds and enzymes), osmoprotectants (free sugars) and cell wall components (polysaccharides). In addition, the occurrence of unusual flavonoids including two new isomeric malonyl esters of eriodictyol-7-O-glucoside was found in LT samples. Data thus obtained allow improving our understanding of ecophysiological mechanisms of cold adaptation of arctic plants.
\end{abstract}

Keywords: Dracocephalum palmatum; fatty acids; essential oil; phenolic compounds; carbohydrates; low-temperature cultivation; antioxidant activity; gas chromatography-mass spectrometry (GC-MS); high performance liquid chromatography with diode array detection and electrospray ionization mass-spectrometric detection (HPLC-DAD-ESI-MS) 


\section{Introduction}

Environmental stress is one of the most important factors limiting the productivity of the majority of economically important crops [1]. Extreme growth conditions can damage the plant habitat, their inner ultrastructure and biochemical composition, causing dramatic changes incompatible with the functions of living organisms [2]. To elevate their vitality, plants have developed the remarkable ability to adapt to severe environmental conditions. These specific potentials have allowed the use of plants as crops even in areas with extremely uncomfortable climate conditions [3].

The territories of the Arctic floristic region of Siberia and the Republic of Sakha (Yakutia) belong to an area of high-risk farming due to unfavorable environmental conditions complicating the implementation of agronomic measures. In the period of maximum growth (vegetation) of agricultural plants (May-September), short-term drops of night temperatures are possible from +2 (July) to $-10{ }^{\circ} \mathrm{C}$ (May and September) [4]. To understand agronomical events in regions with similar weather conditions, it is necessary to use specific cultures that are particularly resistant to the effects of extreme abiotic factors, including temperature. Dracocephalum palmatum Steph. ex Willd. (syn. D. schelechowii Turcz. ex Ledeb., Ruyschiana palmata (Steph. ex Willd.) House, palmate dragonhead) is an example of a widespread species in the Lamiaceae family in the northern part of Siberia (Aldansky, Indigirsky and Kolymsky floral regions) in the permafrost territory and within the Arctic Circle in the range of the Arctic floristic region with a high ecological adaptability [5]. Increased resistance to the effects of chilling temperatures and short-term frosts characterizes this plant species, and it can therefore be defined as a cold-tolerant plant [6].

The herb D. palmatum has economic value as a medicinal plant and in the food industry as a spice and tea component; therefore, D. palmatum is cultivated in the territory of the modern Republic of Sakha (Yakutia) [7]. Early investigations have shown that D. palmatum is characterized by the presence of various groups of natural compounds, including phenylpropanoids, flavonoids, coumarins and triterpenes $[8,9]$. The pronounced antioxidant activity of D. palmatum extracts due to the presence of flavone glycosides of luteolin and apigenin explains its application in medical practice as a hepatoprotective remedy [8]. It should be noted that the use of plant species of the genus Dracocephalum in human households is common occurrence. D. moldavica L. is the most famous Dracocephalum species, which is the object of large-tonnage production as an essential oil source and medicinal plant [10]. Moreover, the traditional medicinal plants D. heterophyllum Benth and D. tanguticum Maxim. are widely used in the medical systems of China and Tibet for the treatment of asthma, bronchitis, gastropathies and hepatitis [11]. In this regard, the application of the local plant species D. palmatum as a food and medicinal preparation in the territory of the north of Siberia is quite justified.

Previous research studies have shown the influence of different types of abiotic stress factors on the essential oil content of Dracocephalum plants. Alaei et al. reported that high levels of salinity may have resulted in a two-fold increase in the amount of essential oil in D. moldavica herb [12]. Studies have also demonstrated that stress levels due to rising water resulted in the decrease of essential oil amounts [13]. It is generally accepted that essential oils are the principal components of Dracocephalum plants, similar to D. heterophyllum [14], D. moldavica [15], D. kotchii [16] and others [11]. However, it should not be forgotten that there are many important natural components that are lipophilic (fatty acids and terpenoids) and hydrophilic in nature (phenolics and carbohydrates) that were identified in the Dracocephalum genus [11]. There is a complete lack of scientific information about the effect of cold stress on chemical components of non-"essential oil"-nature in Dracocephalum species, making it impossible to understand the fundaments of its adaptive process. Possession of the composite data of both lipophilic and hydrophilic compounds variation in Dracocephalum species will be useful for creation of an effective strategy for maximizing the production of secondary metabolites.

The present study was designed to understand the physiological mechanism of cold tolerance of $D$. palmatum. The chemical responses of $D$. palmatum seedlings were estimated by analyzing the phytochemical profile of plants cultivated under low (LT) and normal temperature (NT). The following lipophilic groups of compounds were chosen as markers of lipidome homeostasis: chlorophylls 
and carotenoids due to their role as important and critical biomolecules in photosynthesis with function of light absorbance and light energy transformation; fatty acids as components responsible for the liquid properties of plant cell membranes; and essential oils as a group of structurally variable components with functions closely related to leaf ontogeny and possible role as plant growth regulators. Due to the strong relationship between cold stress level and production of reactive oxygen level in plant cells, the composition of antioxidative components as phenolics was also analyzed. Upon further investigation, particular attention was paid to the profile of the osmoprotectant components (free sugars) and cell wall polymers (polysaccharides). Some physiological parameters such as electrolyte leakage, malondialdehyde concentration and activity levels of superoxide dismutase and catalase in plant tissue were also determined. This research allows improving the theoretical knowledge in the field of ecophysiological adaptation of D. palmatum and helps to estimate the usefulness of cold-temperature cultivation of the arctic plants.

\section{Results and Discussion}

\subsection{Phenotypic Changes, Electrolyte Leakage, Photosynthetic Pigment Content and Parameters of Photosynthesis of D. palmatum during Low-Temperature (LT) Cultivation}

We investigated the phenotypic response of D. palmatum to low-temperature (LT) stress. Seedlings were cultivated in growth chambers with photoperiod of $16 \mathrm{~h}$ light $/ 8 \mathrm{~h}$ dark installed under normal temperature conditions $\left(20^{\circ} \mathrm{C} ; \mathrm{NT}\right)$ for two months. One group of seedlings remained under normal conditions and another group was transferred and subjected to LT $\left(1^{\circ} \mathrm{C}\right)$ for 20 days. The level of LT exposure was close to cold-down periods affected by D. palmatum plants in his natural habitat. The time-frame was chosen to avoid the visible plant damages caused by long-term LT application. To evaluate whether period can be applied successfully, 10-30 days LT impact was used. As a result, it was demonstrated that the duration of $\mathrm{LT}\left(1^{\circ} \mathrm{C}\right)$ should not exceed 20 days.

After the 20-day period, the seedlings grown in $20^{\circ} \mathrm{C}$ were at a height where the plant stems reach an average of $100 \mathrm{~mm}$. During the cold treatment at $1^{\circ} \mathrm{C}$, the seedlings were stockier, with the height of the plant stems reaching an average of $80 \mathrm{~mm}$. A significant increase in the yield of fresh herb was not observed, but leaves of the LT seedlings were a saturated green color and the areas of young leaves were not different from the leaves of the group with moderate temperature conditions.

To evaluate the extent of cell damage caused by cold stress in LT seedlings, electrolyte leakage was measured (Table 1). The D. palmatum plants after 20 days of LT exposure presented 1.44-fold higher electrolyte leakage than normal temperature plants, which suggests that the membrane is likely to be impaired in these seedlings subjected to cold stress [2].

Table 1. Electrolyte leakage (percent of total electrolytes $\pm \mathrm{SD}$ ), photosynthetic pigments content $(\mu \mathrm{g} / \mathrm{g}$ of fresh leaf weight $(\mathrm{FW}) \pm$ standard deviation (SD)), carbon assimilation rate $\left(\mu \mathrm{M} \mathrm{CO}_{2} / \mathrm{m}^{2} \cdot \mathrm{s} \pm \mathrm{SD}\right)$ and effective quantum yield of PSII $\left(\mathrm{F}_{\mathrm{v}} / \mathrm{F}_{\mathrm{m}} ; \pm \mathrm{SD}\right)$ in $D$. palmatum leaves cultivated under normal $\left(20^{\circ} \mathrm{C}\right)$ and low $\left(1{ }^{\circ} \mathrm{C}\right)$ temperatures. ${ }^{1}$

\begin{tabular}{|c|c|c|}
\hline \multirow{2}{*}{ Parameter } & \multicolumn{2}{|c|}{ Temperature $\left({ }^{\circ} \mathrm{C}\right)$} \\
\hline & 20 & 1 \\
\hline Electrolyte leakage, $\%$ of total electrolytes & $18.2 \pm 0.9^{\mathrm{a}}$ & $26.7 \pm 1.4^{\mathrm{a}}$ \\
\hline Chlorophyll a content $\left(\mathrm{Chl}_{\mathrm{a}}\right), \mu \mathrm{g} / \mathrm{g}$ FW & $273.45 \pm 9.29^{a}$ & $406.19 \pm 13.40^{\mathrm{a}}$ \\
\hline Chlorophyll b content $\left(\mathrm{Chl}_{\mathrm{b}}\right), \mu \mathrm{g} / \mathrm{g}$ FW & $75.85 \pm 2.50^{\mathrm{a}}$ & $141.21 \pm 4.79^{\mathrm{a}}$ \\
\hline Total chlorophylls content $(\Sigma \mathrm{Chl}), \mu \mathrm{g} / \mathrm{g}$ FW & 349.30 & 547.40 \\
\hline $\mathrm{Chl}_{\mathrm{a}} / \mathrm{Chl}_{\mathrm{b}}$ & 3.61 & 2.88 \\
\hline Pheophytin a content, $\mu \mathrm{g} / \mathrm{g}$ FW & $6.01 \pm 0.16^{\mathrm{a}}$ & $7.06 \pm 0.14^{a}$ \\
\hline Pheophytin b content, $\mu \mathrm{g} / \mathrm{g}$ FW & $4.57 \pm 0.10^{\mathrm{a}}$ & $5.64 \pm 0.11^{\mathrm{a}}$ \\
\hline Total pheophytins content, $\mu \mathrm{g} / \mathrm{g}$ FW & 10.58 & 12.70 \\
\hline Carotenoids content (Car), $\mu \mathrm{g} / \mathrm{g}$ DW & $36.86 \pm 1.07^{\mathrm{a}}$ & $53.31 \pm 1.55^{\mathrm{a}}$ \\
\hline$\Sigma \mathrm{Chl} / \mathrm{Car}$ & 9.48 & 10.27 \\
\hline Carbon assimilation rate, $\mu \mathrm{M} \mathrm{CO}_{2} / \mathrm{m}^{2} \cdot \mathrm{s}$ & $8.3 \pm 0.8^{b}$ & $5.8 \pm 0.4^{\mathrm{b}}$ \\
\hline $\mathrm{F}_{\mathrm{v}} / \mathrm{F}_{\mathrm{m}}$ & $0.62 \pm 0.04^{b}$ & $0.54 \pm 0.03^{b}$ \\
\hline
\end{tabular}

1 Averages \pm standard deviations were obtained from three $\left({ }^{\mathrm{a}}\right)$ or ten $\left(^{\mathrm{b}}\right)$ different experiments. 
The photosynthetic pigments from the leaves of the three groups were measured (chlorophylls, pheophytins, and carotenoids). Total chlorophylls and carotenoid concentration of the LT group was significantly higher ( 547.40 and $53.31 \mu \mathrm{g} / \mathrm{g}$ FW, respectively) than in NT group (349.30 and $36.86 \mathrm{\mu g} / \mathrm{g} \mathrm{FW}$, respectively), indicating that the photosynthetic pigment levels might contribute to the difference in the photosynthetic capacity among the temperature conditions [17,18]. In contrast, total content of pheophytins in LT plants remained almost unchanged. The extent of pheophytin accumulation under LT stress can play a key role as a measure of chlorophyll damage, which, in this case, is not observed. The ratio of chlorophyll a and $b\left(\mathrm{Chl}_{\mathrm{a}} / \mathrm{Chl}_{\mathrm{b}}\right)$ in NT group was 3.61 and reduced by $20.2 \%$ under LT conditions. By contrast, the ratio of total chlorophyll content ant total carotene content ( $\Sigma \mathrm{Chl} / \mathrm{Car}$ ) in D. palmatum plants under LT stress was 10.27 , which was $8.3 \%$ higher than in NT plants. These changes showed that the LT treatment caused the reorientation of chlorophyll synthesis also with respect to total carotene level. It is also an indicator of a shift in content of light-harvesting complex 2 of a leaf photosystem caused by the impact of the stress factors [19].

The value of carbon assimilation rate in LT plants was lower $\left(5.8 \mu \mathrm{M} \mathrm{CO}_{2} / \mathrm{m}^{2} \cdot \mathrm{s}\right)$ than in plant cultivated at normal temperature $\left(8.3 \mu \mathrm{M} \mathrm{CO}_{2} / \mathrm{m}^{2} \cdot \mathrm{s}\right)$. In addition, the effective quantum yield of PSII $\left(\mathrm{F}_{\mathrm{v}} / \mathrm{F}_{\mathrm{m}}\right)$ in plants exposed to LT was slightly lower than the value of NT plants, demonstrating inhibition of photosynthetic processes under cold temperature. A possible explanation given by us for the differences of photosynthesis rate and chlorophyll content in LT plants was the ability of D. palmatum to accumulate chlorophylls while low rate of its cold-induced degradation.

The known data demonstrate that, at the seedling stage, the impact of chilling stress increases the concentration of the accessory pigments (chlorophyll $\mathrm{b}$ and carotenoids) when compared to chlorophyll a, most likely to increase the photon capture [20]. Moreover, in the case of cold-tolerant lines of crops, more chlorophylls accumulate under cold stress than cold sensitive lines of crops [21]. The results showed that D. palmatum adapted to the environmental temperature and can be grown and perform better under low-temperature conditions.

\subsection{Changes of the Fatty Acids of D. palmatum during LT-Cultivation}

The influence of temperature on the composition of fatty acids in D. palmatum was investigated. The total lipid fraction yield of D. palmatum grown under NT was $1.24 \%$ (of dry plant weight; DW) and the fatty acid composition was characterized by high amounts of palmitic acid (27.9\%), linolenic acids (14.6\%), linoleic acid (14.1\%) and oleic acid (11.3\%) (Table 2). Concerning the amount of fatty acids in other species of the Dracocephalum genus, the fatty acid composition of $D$. kotschyi oil is composed of a high amount of polyunsaturated fatty acids and contains linolenic acid $(61.2 \%)$ as the predominant fatty acid followed by oleic (18.1\%) and linoleic (13.5\%) acids [22]. The amount of linolenic acid in D. moldavica oil was 59.4\% [23]. These results are in accordance with previous data regarding the Lamiaceous plant fatty acid profile where the authors demonstrated the close ratio of the aforementioned acids in herbs [24,25].

The effect of LT environments on D. palmatum resulted in the increase of the total lipid fraction yield to $3.22 \%$ DW and the decrease in the relative amount of saturated acids compared with normal temperature conditions (specifically, the amounts of tridecylic, palmitic and arachidic acids were reduced 2.8, 2.5 and 9 times, respectively) and an increase in the amount of unsaturated fatty acids ( $\gamma$-linoleic, gondoic and erucic acids increased 3.5, 1.9 and 1.7 times, respectively). The influence of LT conditions on the D. palmatum caused a shift in the saturated/unsaturated ratio compared with cultivation in NT (24.0/75.0 vs. 53.3/46.5). Saturated palmitic acid was the predominant fatty acid in D. palmatum cultivated in NT conditions $(27.9 \%)$, while polyunsaturated linoleic acid dominated in samples that grew under LT conditions (19.3\%).

Fatty acids play an important role in the protection of cell membrane against negative effects of long-tern cold exposure [26]. The dominant effect of LT on the lipid composition of cell membranes is the rising level of unsaturated components (e.g., fatty acids) which makes membrane more fluid [27]. 
This is confirmed by the fact of high content of unsaturated fatty acids $(75 \%)$ in D. palmatum herb cultivated under cold temperature.

Table 2. Fatty acids (FA) composition of D. palmatum herb under different temperatures of cultivation (percentage of total FA content).

\begin{tabular}{ccc}
\hline Compound & \multicolumn{2}{c}{ Temperature $\left({ }^{\circ} \mathbf{C}\right)$} \\
\cline { 2 - 3 } & $\mathbf{2 0}$ & $\mathbf{1}$ \\
\hline Pelargonic acid (9:0) & 0.1 & Tr. \\
Capric acid (10:0) & 0.2 & Tr. \\
Lauric acid (12:0) & 5.7 & 3.2 \\
Tridecylic acid (13:0) & 1.4 & 0.5 \\
Myristic acid (14:0) & 2.7 & 1.7 \\
Pentadecylic acid (15:0) & 0.4 & 0.3 \\
Palmitic acid (16:0) & 27.9 & 11.2 \\
Palmitoleic acid (16:1) & 3.8 & 6.9 \\
Margaric acid (17:0) & 1.8 & 1.4 \\
Stearic acid (18:0) & 8.0 & 5.2 \\
Oleic acid (18:1 $\omega-9)$ & 11.3 & 18.3 \\
Linoleic acid (18:2 $\omega-6)$ & 14.1 & 19.3 \\
$\alpha-$ Linolenic acid (18:3 $\omega-3)$ & 12.5 & 18.2 \\
$\gamma$-Linolenic acid (18:3 $\omega-6)$ & 2.1 & 7.4 \\
Arachidic acid (20:0) & 4.5 & 0.5 \\
Gondoic acid (20:1 $\omega-9)$ & 2.0 & 3.7 \\
Behenic acid (22:0) & 0.5 & Tr. \\
Erucic acid (22:1 $\omega-9)$ & 0.7 & 1.2 \\
Lignoceric acid (24:0) & 0.1 & Tr. \\
Total & 99.8 & 99.0 \\
Saturated FA & 53.3 & 24.0 \\
Unsaturated FA & 46.5 & 75.0 \\
Monounsaturated FA & 17.8 & 30.1 \\
Polyunsaturated FA & 28.7 & 44.9 \\
\hline
\end{tabular}

\subsection{Changes of the Essential Oil Profile of D. palmatum during LT-Cultivation}

The samples of D. palmatum herbal essential oil (EO) were isolated by hydrodistillation and the composition was determined for the first time after gas chromatography-mass spectrometry (GC/MS) analysis. EO are greenish liquids characterized by specific smells caused by the presence of odoriferous components. Thirty-eight compounds were identified in three samples of EO from D. palmatum cultivated under different temperatures, including aliphatic compounds, simple phenols, monoterpenes and sesquiterpenes (Table 3).

The yield of the EO was $1.1 \%$ for the sample cultivated in moderate environments $\left(20^{\circ} \mathrm{C}\right)$ and $3.7 \%$ for D. palmatum grown in LT environments. There were no significant differences in the quantitative amounts of aliphatic compounds and simple phenols at both temperatures of cultivation. The predominance of bicyclic monoterpene trans-pinocamphone was noticed at all temperature conditions ranging from $37.9 \%$ to $40.7 \%$. The effect of LT environments on D. palmatum EOs resulted in a slight increase in the amount of monoterpenes and a significant decrease of total sesquiterpenes compared with growth under normal temperature conditions. Thus, the amount of camphene, cis-pinocarveol and cis-pinocarvyl acetate increased 2, 2.5 and 1.8 times compared with samples grown at $20^{\circ} \mathrm{C}$. A decrease in the levels of $\alpha$-tujene, $\beta$-myrcene, phellandral and $p$-mentha-1,4-dien-7-ol at 1.5, 3,2 and 4 times, respectively, was noted.

The total amount of sesquiterpenes decreased 2.9 times compared with samples grown under normal temperature conditions. It can be concluded that temperature environmental conditions should be carefully considered in the cultivation of $D$. palmatum to get the desired concentrations of terpenoids. 
Table 3. Essential oil (EO) composition (percentage of total component content) of D. palmatum herb under different temperatures of cultivation.

\begin{tabular}{|c|c|c|c|c|}
\hline \multirow{2}{*}{ Compound } & \multirow{2}{*}{ RI } & \multirow{2}{*}{$\mathrm{MI}^{\mathrm{a}}$} & \multicolumn{2}{|c|}{ Temperature $\left({ }^{\circ} \mathrm{C}\right.$} \\
\hline & & & 20 & 1 \\
\hline \multicolumn{5}{|c|}{ Aliphatic compounds } \\
\hline Isoamyl acetate & 875 & i, ii, iii & 0.6 & 0.5 \\
\hline Subtotal & & & 0.6 & 0.5 \\
\hline \multicolumn{5}{|c|}{ Simple phenols } \\
\hline p-Cymene & 1024 & i, ii, iii & 1.7 & 1.8 \\
\hline$p$-Cymene-8-ol & 1186 & $\mathrm{i}, \mathrm{ii}$ & 1.9 & 2.0 \\
\hline$p$-Cumenol & 1222 & i, ii, iii & 0.4 & 0.4 \\
\hline$m$-Cumenol & 1225 & $\mathrm{i}, \mathrm{ii}$ & 0.1 & 0.1 \\
\hline Cuminaldehyde & 1241 & i, ii, iii & 1.2 & 1.2 \\
\hline Subtotal & & & 5.3 & 5.5 \\
\hline \multicolumn{5}{|c|}{ Monoterpenes } \\
\hline$\alpha$-Thujene & 926 & i, ii & 0.6 & 0.4 \\
\hline$\alpha$-Pinene & 932 & i, ii, iii & 1.1 & 1.2 \\
\hline Camphene & 947 & i, ii, iii & 0.1 & 0.2 \\
\hline Sabinene & 973 & i, ii, iii & 2.5 & 2.0 \\
\hline$\beta$-Pinene & 975 & i, ii, iii & 8.6 & 9.0 \\
\hline$\beta$-Myrcene & 991 & i, ii, iii & 0.6 & 0.2 \\
\hline Pseudolimonene & 1003 & $\mathrm{i}, \mathrm{ii}$ & 0.3 & 0.2 \\
\hline$\beta$-Phellandrene & 1027 & i, ii, iii & 4.8 & 5.2 \\
\hline Limonene & 1029 & i, ii, iii & 1.8 & 1.8 \\
\hline 1,8-Cineol & 1031 & i, ii, iii & 5.5 & 5.8 \\
\hline$\gamma$-Terpinene & 1058 & i, ii, iii & 0.2 & 0.3 \\
\hline Linalool & 1100 & i, ii, iii & 1.2 & 1.4 \\
\hline$\beta$-Pinone & 1105 & $\mathrm{i}, \mathrm{ii}$ & 0.8 & 1.0 \\
\hline trans-Pinocarveol & 1138 & i, ii, iii & 1.0 & 1.4 \\
\hline trans-Pinocamphone & 1161 & $\mathrm{i}, \mathrm{ii}$ & 37.9 & 40.7 \\
\hline cis-Pinocamphone & 1175 & i, ii & 8.0 & 8.7 \\
\hline cis-Pinocarveol & 1186 & $\mathrm{i}, \mathrm{ii}$ & 0.2 & 0.5 \\
\hline Terpinene-4-ol & 1177 & i, ii, iii & 0.5 & 0.4 \\
\hline Myrtenol & 1197 & $\mathrm{i}, \mathrm{ii}$ & 2.7 & 3.3 \\
\hline Phellandral & 1276 & $\mathrm{i}, \mathrm{ii}$ & 0.2 & 0.1 \\
\hline Bornyl acetate & 1287 & i, ii, iii & 0.3 & 0.2 \\
\hline trans-Pinocarvyl acetate & 1301 & $\mathrm{i}, \mathrm{ii}$ & 1.8 & 2.0 \\
\hline cis-Pinocarvyl acetate & 1315 & $\mathrm{i}, \mathrm{ii}$ & 0.4 & 0.7 \\
\hline Myrtenyl acetate & 1327 & i, ii, iii & 3.5 & 3.7 \\
\hline$p$-Mentha-1,4-dien-7-ol & 1329 & $\mathrm{i}, \mathrm{ii}$ & 0.4 & 0.1 \\
\hline Subtotal & & & 85.0 & 90.8 \\
\hline \multicolumn{5}{|c|}{ Sesquiterpenes } \\
\hline$\beta$-Caryophyllene & 1420 & i, ii, iii & 1.0 & 0.4 \\
\hline$\gamma$-Cadinene & 1518 & $\mathrm{i}, \mathrm{ii}$ & 0.5 & Tr. \\
\hline Germacrene B & 1560 & $\mathrm{i}, \mathrm{ii}$ & 0.7 & 0.1 \\
\hline Caryophyllene oxide & 1587 & i, ii, iii & 1.8 & 0.5 \\
\hline Viridiflorol & 1594 & $\mathrm{i}, \mathrm{ii}$ & 3.2 & 1.6 \\
\hline$\alpha$-Cadinol & 1659 & $\mathrm{i}, \mathrm{ii}$ & 1.2 & 0.3 \\
\hline Germacrone & 1696 & $\mathrm{i}, \mathrm{ii}$ & 0.6 & 0.2 \\
\hline Subtotal & & & 9.0 & 3.1 \\
\hline Total & & & 99.9 & 99.9 \\
\hline
\end{tabular}

a Methods of identification: i, retention index; ii, mass spectrum; iii, co-injection with authentic sample. Tr., traces $(<0.1 \%)$. 
The literature regarding the chemical composition of the EO of the Dracocephalum genus indicates the similarity of the volatile compounds. Most dominant compounds of the Dracocephalum genus related to monoterpenes. D. moldavica EO is the most studied. The main components were acyclic monoterpenes E-citral (30.4\%), geranyl acetate (29.6\%) and neral (22.1\%) [28]. Other isomers of citral (geranial $(63.4 \%)$, limonene $(23.4 \%)$ and $p$-menth-1-en-9-ol $(4.4 \%)$ ) dominated the EOs from the aerial portion of D. subcapitatum [29]. The predominance of the acyclic monoterpenes perilla aldehyde and limonene was revealed in the EO from the aerial portions of D. surmondinum ( $54.3 \%$ and $30.1 \%$, respectively) [30], D. multicaule ( $71.5 \%$ and $28.1 \%$, respectively) [31] and D. polychaetum (63.4\% and $22.1 \%$, respectively) [32]. Other acyclic monoterpenes such as $p$-mentha-1,8-dien-10-al $(39.2 \%)$, limonene $(17.0 \%)$ and geranial $(4.6 \%)$ prevailed in the EO from the aerial portion of D. foetidum [33]. The EO from the aerial portion of D. heterophyllum contained citronellol $(74.9 \%)$, citronellyl formate $(6.7 \%)$ and citronellal (6.7\%) [34]. Volatile constituents of the aerial portion of D. peregrinum contained monocyclic monoterpene 1,8-cineol (18.5\%), $\alpha$-pinene $(8.4 \%)$ and limonene $(5.8 \%)$ [35]. The predominance of acyclic and bicyclic monoterpenes was noticed in the EO from the aerial portion of $D$. kotschyi, including neral (11\%), $\alpha$-citral (12\%) and $\alpha$-pinene (10\%) [36]. D. aucherry was a species with a prevalence of $\mathrm{EO}$ from the flowering shoots that contained bicyclic monoterpene sabinene (55.2\%), germacrone (9.9\%) and $\alpha$-thujene (5.5\%) [37]. Another species with a predominance of bicyclic monoterpenes in the EO from aerial portion was D. wallichii (D. speciosum) (trans-pinocarvyl acetate $(60.5 \%)$ and cis-pinocarvyl acetate $(5.7 \%))$ [38].

Temperature levels have been previously reported to influence the EO amount in several aromatic crops of the Lamiaceous group [39]. A decrease in temperature may favor the accumulation of various groups of volatile terpenoids in EO glands on the leaf surface [40]. In sage leaves (Salvia officinalis L.), the largest percentage of monoterpenes was observed in the cold period of cultivation (October) [41]. The same effect on monoterpene accumulation was reported for peppermint EO (Mentha piperita L.) isolated from the plants grown at LTs [42,43]. The data obtained indicated a similarity of the temperature-induced physiological responses previously detected in Lamiaceous plants and D. palmatum. In this way, the production of EO in D. palmatum is not only exerted in a development-specific fashion but is also highly susceptible to modulation through temperature regulation.

\subsection{Changes of Phenolic Compounds of D. palmatum during LT-Cultivation}

The methanol extracts of $D$. palmatum were analyzed by reversed phase high performance liquid chromatography with diode array detection and electrospray ionization mass-spectrometric detection (RP-HPLC-DAD-ESI-MS) in both negative and positive ionization modes. The HPLC with ultraviolet detection (HPLC-UV) map and HPLC-DAD chromatogram are shown in Figure 1, and chromatographic parameters, UV and ESI-MS data are in Table 4. By comparing the retention times $\left(t_{R}\right), U V$ and ESI-MS spectra with those of references substances and literature data, 32 components were identified in all plant samples ( 23 components in NT samples and 32 components in LT sample), including two simple phenolic glycosides (1 and $\mathbf{2})$, four caffeic acid derivatives or phenylpropanoids (3-5 and 19) and 26 flavonoids (6-18 and 20-32) as glycosides and aglycones.

Two simple phenolic glycosides, compounds $\mathbf{1}$ and 2, were detected in D. palmatum for the first time. The quasi-molecular ions were $[\mathrm{M}+\mathrm{H}]^{+}$as well as sodium adducts $[\mathrm{M}+\mathrm{Na}]^{+}$in positive ion mode; both compounds had weak ionization in negative ion mode. Compound $\mathbf{2}$ was characterized as arbutin (hydroquinone-O-glucoside) due to intense $[\mathrm{M}+\mathrm{Na}]^{+}$at $m / z 295$ and specific absorbance in the UV spectrum compared with the reference compound [44]. Compound 1 gave the sodium adduct $[\mathrm{M}+\mathrm{Na}]^{+}$and quasi-molecular ion $[\mathrm{M}+\mathrm{H}]^{+}$at $m / z 381$ and 352, respectively (i.e., 86 amu more than arbutin indicating malonyl-derivative of 2 tentatively characterized as $O$-malonyl-arbutin) [45]. Data in the literature data demonstrated that the arbutin and its esters are rare components for the Lamiaceae family. Only Origanum majorana L. (formerly Majorana hortensis Moench.) is known as a good source of arbutin (2) as other Origanum species (O. onites L., O. microphyllum (Benth.) Vogel, O. saccatum P.H. 
Davis, O. solymicum P.H. Davis) only contain trace amounts of 2 [46]. Arbutin ester 1 was detected only in D. moldavica of Mexican origin [45].
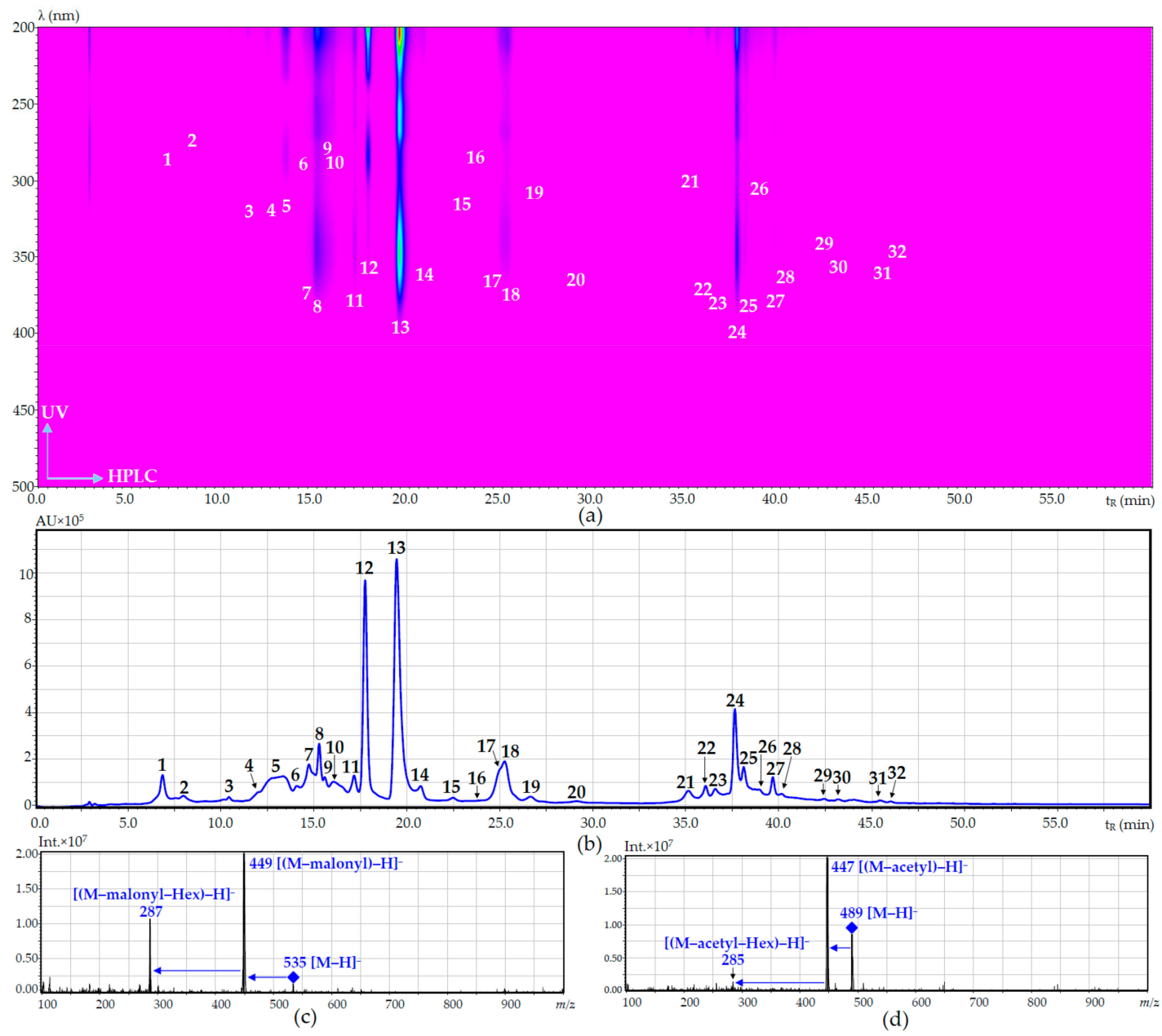

Figure 1. HPLC-UV map (a); and RP-HPLC-DAD chromatogram at $280 \mathrm{~nm}$ (b) of low-temperature sample of D. palmatum herb; ESI-MS spectra of unknown compounds 6 (eriodictyol-O-malonyl-hexoside) and 20 (luteolin-O-acetyl-hexoside) presented at (c,d), respectively. The numbers in the Figure 1a,b correspond to the compounds indicated in Table 4. AU, absorbance units; Int., signal intensity.

Four chromatographic peaks $(3,4,5$ and 19) with the same UV spectra as the standards of 5-O-caffeoylquinic acid, 3-O-caffeoylquinic acid, caffeic acid and rosmarinic acid were detected in all samples of $D$. palmatum. Two of them (3 and 5) showed the $[\mathrm{M}-\mathrm{H}]^{-}$ions at $m / z 353$ and one (19) at $m / z$ 359. Components $\mathbf{4}, \mathbf{5}$ and $\mathbf{1 9}$ were previously detected in D. palmatum [8], and $\mathbf{3}$ was discovered in this species for the first time in this study.

Flavone glycosides as usual components of the flavonoid complex in the Dracocephalum genus [11] were presented as derivatives of apigenin, acacetin and luteolin widely distributed in Lamiaceae family [47]. Luteolin-7-O-rutinoside (scolymoside, 11), luteolin-7-O-glucoside (cynaroside, 13), luteolin-4'-O-glucoside (14), apigenin-7-O-rutinoside (isorhoifolin, 15), apigenin-7-O-glucoside (cosmosiin, 17), acacetin-7-O-rutinoside (linarin, 22) and acacetin-7-O-glucoside (tilianin, 23) standards allowed the unequivocal identification of these seven flavone glycosides in D. palmatum extracts. Five of these flavonoids (11, 13-15, and 17) have already been characterized as components of D. palmatum [8]. Acacetin derivatives 22 and 23, described in D. palmatum for the first time, are not usual for Dracocephalum genus. Both components were also found in D. foetidum [48], D. moldavica [11] and D. peregrinum $[49,50]$. 
Table 4. HPLC parameters, ultraviolet spectra data (UV) and electrospray ionization mass spectrometry (ESI-MS) data of components 1-32 from D. palmatum herb.

\begin{tabular}{|c|c|c|c|c|c|}
\hline No. & Compound & $t_{R}(\min )$ & $\mathrm{UV}, \lambda_{\max }(\mathrm{nm})$ & ESI-MS $(m / z)$ & $\begin{array}{c}\text { Refs. } \\
\text { Comp. }\end{array}$ \\
\hline 1 & O-Malonyl-arbutin & 6.79 & 280 & $\begin{array}{l}381[\mathrm{M}+\mathrm{Na}]^{+} \\
352[\mathrm{M}+\mathrm{H}]^{+} \\
295[\mathrm{M}+\mathrm{Na}]^{+}\end{array}$ & iii [45] \\
\hline 2 & Arbutin & 7.89 & 280 & $295[\mathrm{M}+\mathrm{Na}]^{+}, 273[\mathrm{M}+\mathrm{H}]^{+}$ & i \\
\hline 3 & 5-O-Caffeoylquinic acid & 10.43 & 331 & $353[\mathrm{M}-\mathrm{H}]^{-}, 183$ & $\mathrm{i}$ \\
\hline 4 & 3-O-Caffeoylquinic acid & 12.03 & 331 & $353[\mathrm{M}-\mathrm{H}]^{-}, 183$ & $\mathrm{i}$ \\
\hline 5 & Caffeic acid & 13.15 & 323 & $179[\mathrm{M}-\mathrm{H}]^{-}$ & i \\
\hline 6 & Eriodictyol-O-malonyl-hexoside (isomer) & 14.09 & 284 & $\begin{array}{c}535[\mathrm{M}-\mathrm{H}]^{-}, \\
449[(\mathrm{M}-\text { malonyl })-\mathrm{H}]^{-} \\
287[(\mathrm{M}-\text { malonyl }-\mathrm{Hex})-\mathrm{H}]^{-}\end{array}$ & - \\
\hline 7 & $\begin{array}{l}\text { Luteolin-7,4'-di-O-rutinoside } \\
\quad \text { (dracopalmaside) }\end{array}$ & 14.87 & $253,265,345$ & $\begin{array}{c}905\left[\mathrm{M}-\mathrm{H}^{-}\right. \\
447[(\mathrm{M}-\mathrm{Rha}-\mathrm{Glc})-\mathrm{H}]^{-} \\
285[(\mathrm{M}-2 \times \mathrm{Rha}-2 \times \mathrm{Glc})-\mathrm{H}]^{-}\end{array}$ & ii [9] \\
\hline 8 & $\begin{array}{l}\text { Luteolin-7-O-rutinoside- } 4^{\prime} \text {-O-glucoside } \\
\text { (cynarotriside) }\end{array}$ & 15.02 & $253,265,345$ & $\begin{array}{c}755[\mathrm{M}-\mathrm{H}]^{-} \\
609[(\mathrm{M}-\mathrm{Rha})-\mathrm{H}]^{-} \\
447[(\mathrm{M}-\mathrm{Rha}-\mathrm{Glc})-\mathrm{H}]^{-} \\
285[(\mathrm{M}-\mathrm{Rha}-2 \times \mathrm{Glc})-\mathrm{H}]^{-}\end{array}$ & ii [9] \\
\hline 9 & Eriodictyol-O-malonyl-hexoside (isomer) & 15.41 & 283 & $\begin{array}{c}535[\mathrm{M}-\mathrm{H}]^{-}, \\
449[(\mathrm{M}-\text { malonyl })-\mathrm{H}]^{-} \\
287[(\mathrm{M}-\text { malonyl }-\mathrm{Hex})-\mathrm{H}]^{-}\end{array}$ & - \\
\hline 10 & Eriodictyol-7-O-rutinoside (eriocitrin) & 16.21 & 284 & $\begin{array}{c}595[\mathrm{M}-\mathrm{H}]^{-} \\
449[(\mathrm{M}-\mathrm{Rha})-\mathrm{H}]^{-} \\
287[(\mathrm{M}-\mathrm{Rha}-\mathrm{Glc})-\mathrm{H}]^{-}\end{array}$ & $\mathrm{i}$ \\
\hline 11 & Luteolin-7-O-rutinoside (scolymoside) & 17.02 & $252,262,345$ & $\begin{array}{c}593[\mathrm{M}-\mathrm{H}]^{-} \\
447[(\mathrm{M}-\mathrm{Rha})-\mathrm{H}]^{-} \\
285[(\mathrm{M}-\mathrm{Rha}-\mathrm{Glc})-\mathrm{H}]^{-}\end{array}$ & $\mathrm{i}$ \\
\hline 12 & Eriodictyol-7-O-glucoside & 17.58 & 283 & $\begin{array}{c}899[2 \mathrm{M}-\mathrm{H}]- \\
449[\mathrm{M}-\mathrm{H}]^{-} \\
287[(\mathrm{M}-\mathrm{Glc})-\mathrm{H}]^{-}\end{array}$ & $\mathrm{i}$ \\
\hline 13 & Luteolin-7-O-glucoside (cynaroside) & 19.48 & $254,267,348$ & $\begin{array}{c}895[2 \mathrm{M}-\mathrm{H}]- \\
447[\mathrm{M}-\mathrm{H}]^{-} \\
285[(\mathrm{M}-\mathrm{Glc})-\mathrm{H}]^{-}\end{array}$ & $\mathrm{i}$ \\
\hline 14 & Luteolin-4'-O-glucoside & 20.64 & 260,335 & $\begin{array}{c}447[\mathrm{M}-\mathrm{H}]^{-} \\
285[(\mathrm{M}-\mathrm{Glc})-\mathrm{H}]^{-}\end{array}$ & $\mathrm{i}$ \\
\hline 15 & Apigenin-7-O-rutinoside (isorhoifolin) & 22.51 & 266,334 & $\begin{array}{c}577[\mathrm{M}-\mathrm{H}]^{-} \\
431[(\mathrm{M}-\mathrm{Rha})-\mathrm{H}]^{-} \\
269[(\mathrm{M}-\mathrm{Rha}-\mathrm{Glc})-\mathrm{H}]^{-}\end{array}$ & $\mathrm{i}$ \\
\hline 16 & Naringenin-7-O-glucoside (prunin) & 23.89 & 283 & $\begin{array}{c}433[\mathrm{M}-\mathrm{H}]^{-} \\
271[(\mathrm{M}-\mathrm{Glc})-\mathrm{H}]^{-} \\
\end{array}$ & $\mathrm{i}$ \\
\hline 17 & Apigenin-7-O-glucoside (cosmosiin) & 24.47 & 267,336 & $\begin{array}{c}863[2 \mathrm{M}-\mathrm{H}]- \\
431[\mathrm{M}-\mathrm{H}]^{-} \\
269[(\mathrm{M}-\mathrm{Glc})-\mathrm{H}]^{-}\end{array}$ & $\mathrm{i}$ \\
\hline 18 & Apigenin-O-hexoside & 25.31 & 265,334 & $\begin{array}{c}431[\mathrm{M}-\mathrm{H}]^{-} \\
269[(\mathrm{M}-\mathrm{Glc})-\mathrm{H}]^{-}\end{array}$ & iii [51] \\
\hline 19 & Rosmarinic acid & 27.26 & 327 & $359[\mathrm{M}-\mathrm{H}]^{-}, 183$ & i \\
\hline 20 & Luteolin-O-acetyl-hexoside & 29.11 & $251,263,346$ & $\begin{array}{c}489[\mathrm{M}-\mathrm{H}]^{-}, \\
447[(\mathrm{M}-\text { acetyl })-\mathrm{H}]^{-}, \\
285[(\mathrm{M}-\text { acetyl }-\mathrm{Hex})-\mathrm{H}]^{-}\end{array}$ & iii [52] \\
\hline 21 & Eriodictyol & 35.03 & 283 & $287[\mathrm{M}-\mathrm{H}]^{-}$ & $\mathrm{i}$ \\
\hline 22 & Acacetin-7-O-rutinoside (linarin) & 36.14 & 267,330 & $\begin{array}{c}591[\mathrm{M}-\mathrm{H}]^{-} \\
445[(\mathrm{M}-\mathrm{Rha})-\mathrm{H}]^{-} \\
283[(\mathrm{M}-\mathrm{Rha}-\mathrm{Glc})-\mathrm{H}]^{-}\end{array}$ & $\mathrm{i}$ \\
\hline 23 & Acacetin-7-O-glucoside (tilianin) & 36.72 & 266,330 & $\begin{array}{c}445[\mathrm{M}-\mathrm{H}]^{-} \\
283[(\mathrm{M}-\mathrm{Glc})-\mathrm{H}]^{-}\end{array}$ & $\mathrm{i}$ \\
\hline 24 & Luteolin & 37.72 & $253,266,347$ & $285[\mathrm{M}-\mathrm{H}]^{-}$ & i \\
\hline 25 & Acacetin-O-acetyl-hexoside & 38.10 & 266,331 & $\begin{array}{c}487[\mathrm{M}-\mathrm{H}]^{-}, \\
445[(\mathrm{M}-\text { acetyl })-\mathrm{H}]^{-}, \\
283[(\mathrm{M}-\text { acetyl }-\mathrm{Hex})-\mathrm{H}]^{-}\end{array}$ & iii [52] \\
\hline
\end{tabular}


Table 4. Cont.

\begin{tabular}{|c|c|c|c|c|c|}
\hline No. & Compound & $t_{R}(\min )$ & $\mathrm{UV}, \lambda_{\max }(\mathrm{nm})$ & ESI-MS $(m / z)$ & $\begin{array}{c}\text { Refs. } \\
\text { Comp. }\end{array}$ \\
\hline 26 & Naringenin & 38.32 & 283 & $271[\mathrm{M}-\mathrm{H}]^{-}$ & $\mathrm{i}$ \\
\hline 27 & Apigenin & 39.75 & 267,336 & $269[\mathrm{M}-\mathrm{H}]^{-}$ & $\mathrm{i}$ \\
\hline 28 & Chrysoeriol & 40.21 & 266,347 & $299[\mathrm{M}-\mathrm{H}]^{-}$ & $\mathrm{i}$ \\
\hline 29 & Acacetin & 42.34 & 267,330 & $283[\mathrm{M}-\mathrm{H}]^{-}$ & $\mathrm{i}$ \\
\hline 30 & Isothymusin & 43.06 & 302,330 & $329[\mathrm{M}-\mathrm{H}]^{-}$ & ii [46] \\
\hline 31 & Salvigenin & 45.81 & 273,330 & $327[\mathrm{M}-\mathrm{H}]^{-}$ & $\mathrm{i}$ \\
\hline 32 & Genkwanin & 46.04 & 267,335 & $283[\mathrm{M}-\mathrm{H}]^{-}$ & $\mathrm{i}$ \\
\hline
\end{tabular}

${ }^{\text {a }}$ Reference compound used: i, commercial sample; ii, isolated compound; iii, literature data.

Two rare di-O-glycosides of luteolin, luteolin-7,4'-di-O-rutinoside (dracopalmaside, 7) and luteolin7-O-rutinoside-4'-O-glucoside (cynarotriside, 8), previously isolated from D. palmatum of natural origin [9] were also detected in plants grown in greenhouse conditions.

Compound 18 was identified as apigenin-O-hexoside according to UV and ESI-MS spectra and literature information [51]. This compound demonstrated the same UV spectra pattern as flavone standards. The ESI-MS deprotonated ion $[\mathrm{M}-\mathrm{H}]^{-}$at $m / z 431$ and the aglycone fragment at $m / z$ 269 revealed the characteristic fragmentation of an apigenin-hexose derivative [53]. Due to the difference in the retention times of $\mathbf{1 8}\left(t_{R} 25.31 \mathrm{~min}\right)$ and apigenin-7-O-glucoside $\left(t_{R} 24.47 \mathrm{~min}\right)$, component 18 may be tentatively determined as apigenin- $4^{\prime}-O$-glucoside, previously identified in Elsholtzia rugulosa Hemsl [51].

Two components, $20\left(t_{R} 29.11 \mathrm{~min}\right)$ and $25\left(t_{R} 38.10 \mathrm{~min}\right)$, detected only in low-temperature samples of $D$. palmatum, were characterized as $O$-acetyl-hexosides of luteolin and acacetin, respectively, according to UV and ESI-MS fragmentation patterns [54]. The presence of acylation in structures 20 and 25 was explained by their late elution compared with deacylated analogs, such as luteolin-7-O-glucoside (13; $\left.\mathrm{t}_{\mathrm{R}} 19.48 \mathrm{~min}\right)$ and acacetin-7-O-glucoside $\left(23 ; \mathrm{t}_{\mathrm{R}} 36.72 \mathrm{~min}\right)$, respectively. The ESI-MS spectra in negative ion mode showed the peaks of the $[\mathrm{M}-\mathrm{H}]^{-}$ions and their deacylated fragments: $489 \rightarrow 447$ for 20 (Figure 1d) and $487 \rightarrow 445$ for 25 , which were useful for the characterization of the type of acyl group as an acetyl-group [53]. The presence of acetylated hexosides of luteolin and acacetin was not shown in D. palmatum previously, but has been described in D. foetidum [48] and D. peregrinum $[49,50]$.

Five compounds were detected within the group of flavanone glycosides, and three of them were identified as eriodictyol-7-O-rutinoside (eriocitrin, 10), eriodictyol-7-O-glucoside (12) and naringenin-7-O-glucoside (prunin, 16) by comparison with standards. Eriodictyol-7-O-glucoside (12) and naringenin-7-O-glucoside (16) were found previously in D. palmatum [8] and D. rupestre [11]. Eriodictyol-7-O-rutinoside (10) was a new component for D. palmatum and in the Dracocephalum genus.

ESI-MS and UV spectra of components 6 and 9 were identical and lead readily to the determination of both compounds as flavanone-O-acyl-hexosides [54]. Based on $m / z$ values, these flavonoids should be isomeric $O$-malonyl-hexosides of eriodictyol. UV and MS product spectra confirmed the identity of 6 and 9 as aglycone using an eriodictyol standard. The type of acyl group (malonyl) was confirmed by the presence of both acylated and deacylated fragments in ESI-MS spectra in negative ion mode (Figure 1c). Known literature regarding glycosides of eriodictyol showed no information about the $O$-malonyl-hexoside of eriodictyol, demonstrating that $\mathbf{6}$ and $\mathbf{9}$ are new isomeric natural compounds. Even though malonyl-glycosyl derivatives of flavonoids are rare components of the Lamiaceae family, they have already been isolated from D. foetidum [48], indicating the ability of the Dracocephalum plant to synthesize acylated flavonoid glycosides.

Nine flavonoid aglycones were detected in D. palmatum samples, including two flavanones (21 and 26) and seven flavones (24, and 27-32). Eight of them were identified by comparing their UV and ESI-MS patterns with reference samples: eriodictyol (21), luteolin (24), naringenin (26), apigenin (27), chrysoeriol (28), acacetin (29), salvigenin (31) and genkwanin (32). Component 30 showed the 
$[\mathrm{M}-\mathrm{H}]^{-}$ion at $m / z 329$ and a specific UV spectrum with maxima at 302 and $330 \mathrm{~nm}$, which are characteristic for isothymusin [55]. Four flavonoid aglycones $(\mathbf{2 1}, \mathbf{2 4}, \mathbf{2 6}$, and 27) were identified in wild samples of D. palmatum [8], while components 28-32 were discovered in this Dracocephalum species for the first time.

These results suggest that the phenolic profile of D. palmatum may be successfully described using the online technique of RP-HPLC-DAD-ESI-MS, which allowed the characterization of 32 components (Figure 2). Although some of the phenolics $(4,5,7,8,11-17,19,21,24,26$, and 27) have been previously described in D. palmatum, others (1-3, 10, 18, 20, 22, 23, 25, and 28-32) have been discovered in this Dracocephalum species for the first time, including two new acylated flavanone glycosides (6 and $\mathbf{9})$.

Application of RP-HPLC-DAD for quantification of components 1-32 in D. palmatum showed that the composition of simple phenols, phenylpropanoids, flavone and flavanone aglycones and glycosides was significantly influenced by abiotic stress signals (e.g., cold-temperature conditions) (Table 5).

The amount of $O$-malonyl-arbutin (1) in a sample cultivated in NT conditions was 3.2 times lower than in cultivars grown in LT environments $(1.24 \mathrm{mg} / \mathrm{g})$. Arbutin content varied insignificantly in the both experimental groups. There were no qualitative differences in phenylpropanoid profiles of all experimental groups. The high amount of both caffeoylquinic acids ( 3 and 4 ) was noticed for the NT group. Their reduction was observed in LT conditions. However, the levels of caffeic (5) and rosmarinic acids (19) were the highest for LT samples and exceeded the amounts in samples from NT by 1.4 and 1.3 times, respectively. It should be noted that the high amount of $\mathbf{1 9}$ was noted earlier for D. kotschyi gathered from cold-temperature environments [56].

Significant changes in the flavonoid profiles of D. palmatum were observed. It has already been mentioned that flavones were represented by acacetin, apigenin and luteolin derivatives with the prevalence of the latter. Luteolin-7-O-glucoside (13) was the dominant flavonoid in NT group $(2.56 \mathrm{mg} / \mathrm{g})$ and LT group $(29.56 \mathrm{mg} / \mathrm{g})$. The highest amounts of other luteolin derivatives such as luteolin-7, $4^{\prime}$-di-O-rutinoside (7), luteolin-7-O-rutinoside-4'-O-glucoside (8), luteolin-4'-O-glucoside (14) and luteolin-O-acetyl-hexoside (20) were noted for $D$. palmatum cultivated in LT environments. In addition, a significant increase in the apigenin derivatives apigenin-7-O-glucoside (17) and apigenin-O-hexoside (18) was observed under the same conditions. It is well known that flavonoid glycosides can be influenced by climate conditions such as temperature. Low temperature enhances total flavonoids, which act as shielding components and are responsible for protecting plants from damage as a result of enzymatic repair inhibition, combined with higher quantities of reactive oxygen species [57,58]. In the present experiment, induced biosynthesis of luteolin glycosides was assumed as a possible response. Furthermore, luteolin glycosides were shown to have higher antioxidant activity than their corresponding apigenin glycosides, underlining their importance in the cold-stress response [59].

The total amounts of minor components such as acacetin derivatives also increased to a maximum with decreasing temperature. It should be noted that acacetin-O-acetyl-hexoside (25) in NT conditions was not detected. The maximum amount of acacetin glycosides was observed in the LT group $(1.41 \mathrm{mg} / \mathrm{g})$ exceeded the amount of the same compounds in NT groups 2.5 times. Data in the literature indicate that the increased amount of methoxylated flavonoids can be paralleled with the increase in $O$-methyltransferase enzyme activity during cold acclimation [60].

The HPLC-detectable glycosides of flavanone types were represented by eriodictyol and naringenin derivatives. Eriodictyol-O-malonyl-hexosides (6 and 9) in NT conditions were not detected, but were revealed in cold-temperature environments. An increase in the amount of eriodictyol-7-Oglucoside (12) and naringenin-7-O-glucoside (16) in the LT group was found when compared to plants from NT. 


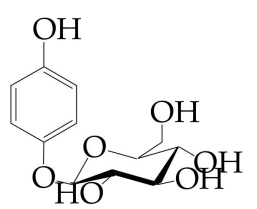

2<smiles>OC1OC2OC(O)C(O2)OC1O</smiles>

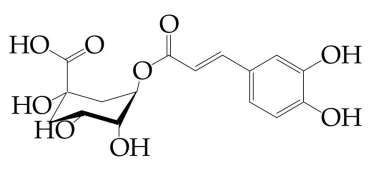

3

но<smiles>O=C(/C=C/c1ccc(O)c(O)c1)OCC1CC(O)C(O)CC1C(=O)O</smiles>

4<smiles>O=C(O)C=CC1CCC(O)C(O)C1</smiles>

5

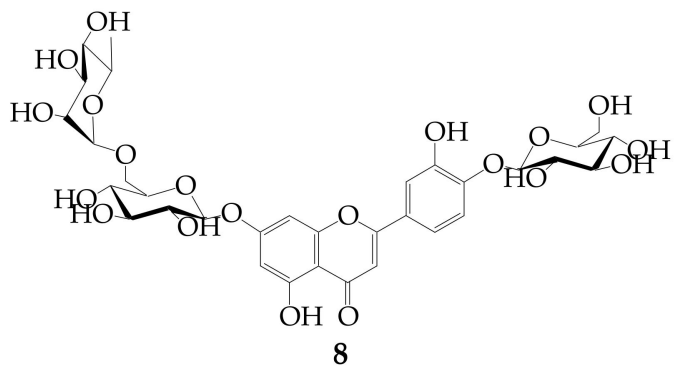

7

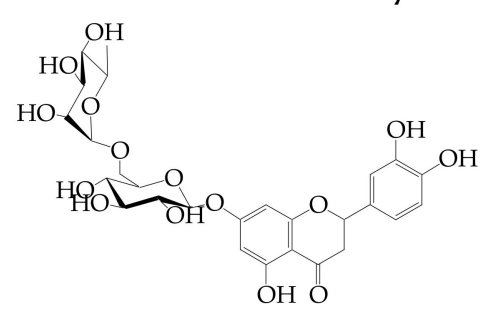

10

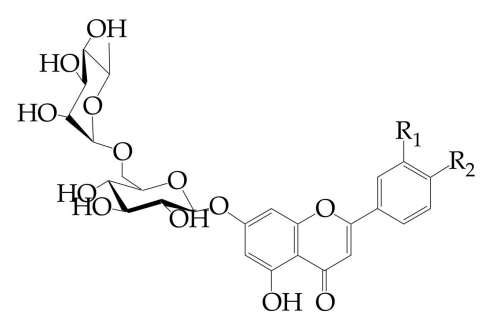

11: $\mathrm{R}_{1}=\mathrm{R}_{2}=\mathrm{OH}$

15: $\mathrm{R}_{1}=\mathrm{H} ; \mathrm{R}_{2}=\mathrm{OH}$

22: $\mathrm{R}_{1}=\mathrm{H} ; \mathrm{R}_{2}=\mathrm{OCH}_{3}$

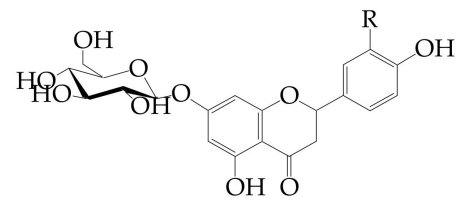

12: $\mathrm{R}=\mathrm{OH}$

16: $\mathrm{R}=\mathrm{H}$<smiles>[R]C1CCC(C2=CC(=O)C3C(O)CC(OCC(=O)O)CC3O2)CC1[R1]</smiles>

13: $\mathrm{R}_{1}=\mathrm{R}_{2}=\mathrm{OH}$

17: $\mathrm{R}_{1}=\mathrm{H} ; \mathrm{R}_{2}=\mathrm{OH}$

23: $\mathrm{R}_{1}=\mathrm{H} ; \mathrm{R}_{2}=\mathrm{OCH}_{3}$

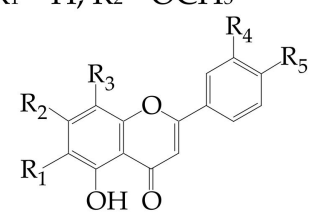

24: $\mathrm{R}_{1}=\mathrm{R}_{3}=\mathrm{H} ; \mathrm{R}_{2}=\mathrm{R}_{4}=\mathrm{R}_{5}=\mathrm{OH}$

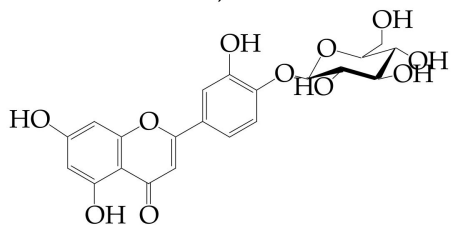

14<smiles></smiles>

21: $\mathrm{R}=\mathrm{OH}$ 26: $\mathrm{R}=\mathrm{H}$<smiles>O=C(/C=C/c1ccc(O)c(O)c1)OC(Cc1ccc(O)c(O)c1)C(=O)O</smiles>

27: $\mathrm{R}_{1}=\mathrm{R}_{3}=\mathrm{R}_{4}=\mathrm{H} ; \mathrm{R}_{2}=\mathrm{R}_{5}=\mathrm{OH}$

28: $\mathrm{R}_{1}=\mathrm{R}_{3}=\mathrm{H} ; \mathrm{R}_{2}=\mathrm{R}_{5}=\mathrm{OH} ; \mathrm{R}_{4}=\mathrm{OCH}_{3}$

29: $\mathrm{R}_{1}=\mathrm{R}_{3}=\mathrm{R}_{4}=\mathrm{H} ; \mathrm{R}_{2}=\mathrm{OH} ; \mathrm{R}_{5}=\mathrm{OCH}_{3}$

19

30: $\mathrm{R}_{1}=\mathrm{R}_{2}=\mathrm{OCH}_{3} ; \mathrm{R}_{3}=\mathrm{R}_{5}=\mathrm{OH} ; \mathrm{R}_{4}=\mathrm{H}$

31: $\mathrm{R}_{1}=\mathrm{R}_{2}=\mathrm{R}_{5}=\mathrm{OCH}_{3} ; \mathrm{R}_{3}=\mathrm{R}_{4}=\mathrm{H}$

32: $\mathrm{R}_{1}=\mathrm{R}_{3}=\mathrm{R}_{4}=\mathrm{H} ; \mathrm{R}_{2}=\mathrm{OCH}_{3} ; \mathrm{R}_{5}=\mathrm{OH}$

Figure 2. Structures of phenolic compounds 2-5, 7, 8, 10-17, 19, 21-24, and 26-32 detected in D. palmatum herb. 
Table 5. Content of phenolic compounds $(\mathrm{mg} / \mathrm{g} \mathrm{DW} \pm \mathrm{SD})$ in D. palmatum herb under different temperatures of cultivation. ${ }^{1}$

\begin{tabular}{|c|c|c|}
\hline \multirow{2}{*}{ Compound (No of Compounds) } & \multicolumn{2}{|c|}{ Temperature $\left({ }^{\circ} \mathrm{C}\right)$} \\
\hline & 20 & 1 \\
\hline \multicolumn{3}{|c|}{ Simple phenols } \\
\hline O-Malonyl-arbutin (1) & $0.39 \pm 0.01^{\mathrm{a}}$ & $1.24 \pm 0.02^{\mathrm{a}}$ \\
\hline Arbutin (2) & $0.17 \pm 0.00$ & $0.22 \pm 0.00$ \\
\hline Subtotal & 0.56 & 1.46 \\
\hline \multicolumn{3}{|c|}{ Phenylpropanoids } \\
\hline 5-O-Caffeoylquinic acid (3) & $0.09 \pm 0.00$ & $0.05 \pm 0.00$ \\
\hline 3-O-Caffeoylquinic acid (4) & $0.11 \pm 0.00$ & $0.09 \pm 0.00$ \\
\hline Caffeic acid (5) & $0.61 \pm 0.02$ & $0.84 \pm 0.02$ \\
\hline Rosmarinic acid (19) & $1.26 \pm 0.03$ & $1.68 \pm 0.04$ \\
\hline Subtotal & 2.07 & 2.66 \\
\hline \multicolumn{3}{|c|}{ Flavone glycosides. Apigenin derivatives } \\
\hline Apigenin-7-O-rutinoside (isorhoifolin, 15) & $1.11 \pm 0.03$ & $0.56 \pm 0.02$ \\
\hline Apigenin-7-O-glucoside (cosmosiin, 17) & $0.53 \pm 0.01$ & $6.54 \pm 0.17$ \\
\hline Apigenin-O-hexoside (18) & $0.47 \pm 0.01^{\mathrm{b}}$ & $8.34 \pm 0.18^{b}$ \\
\hline Subtotal & 2.11 & 15.44 \\
\hline \multicolumn{3}{|c|}{ Flavone glycosides. Acacetin derivatives } \\
\hline Acacetin-7-O-rutinoside (linarin, 22) & $0.04 \pm 0.00$ & $0.06 \pm 0.00$ \\
\hline Acacetin-7-O-glucoside (tilianin, 23) & $0.52 \pm 0.01$ & $1.27 \pm 0.04$ \\
\hline Acacetin-O-acetyl-hexoside (25) & ND & $0.08 \pm 0.00^{c}$ \\
\hline Subtotal & 0.56 & 1.41 \\
\hline \multicolumn{3}{|c|}{ Flavone glycosides. Luteolin derivatives } \\
\hline Luteolin-7,4'-di-O-rutinoside (dracopalmaside, 7) & $0.14 \pm 0.00$ & $0.52 \pm 0.01$ \\
\hline Luteolin-7-O-rutinoside- $4^{\prime}$-O-glucoside (cynarotriside, 8) & $0.82 \pm 0.02$ & $1.75 \pm 0.04$ \\
\hline Luteolin-7-O-rutinoside (scolymoside, 11) & $2.27 \pm 0.07$ & $2.54 \pm 0.07$ \\
\hline Luteolin-7-O-glucoside (cynaroside, 13) & $2.56 \pm 0.07$ & $29.56 \pm 0.78$ \\
\hline Luteolin- $4^{\prime}$-O-glucoside (14) & $0.67 \pm 0.02$ & $9.57 \pm 0.19$ \\
\hline Luteolin-O-acetyl-hexoside (20) & ND & $0.92 \pm 0.02^{d}$ \\
\hline Subtotal & 6.46 & 44.86 \\
\hline \multicolumn{3}{|c|}{ Flavanone glycosides. Eriodictyol derivatives } \\
\hline Eriodictyol-O-malonyl-hexoside (sum of $\mathbf{6}$ and $\mathbf{9}$ ) & ND & $1.84 \pm 0.04^{\mathrm{e}}$ \\
\hline Eriodictyol-7-O-rutinoside (eriocitrin, 10) & $0.21 \pm 0.00$ & $1.35 \pm 0.03$ \\
\hline Eriodictyol-7-O-glucoside (12) & $1.77 \pm 0.03$ & $15.82 \pm 0.33$ \\
\hline Subtotal & 1.98 & 19.01 \\
\hline \multicolumn{3}{|c|}{ Flavanone glycosides. Naringenin derivatives } \\
\hline Naringenin-7-O-glucoside (pruning, 16) & $1.02 \pm 0.02$ & $1.64 \pm 0.03$ \\
\hline Subtotal & 1.02 & 1.64 \\
\hline \multicolumn{3}{|c|}{ Flavone aglycones } \\
\hline Luteolin (24) & $1.19 \pm 0.03$ & $12.94 \pm 0.30$ \\
\hline Apigenin (27) & $0.46 \pm 0.01$ & $1.03 \pm 0.03$ \\
\hline Chrysoeriol (28) & $0.09 \pm 0.00$ & $0.14 \pm 0.00$ \\
\hline Acacetin (29) & ND & $0.18 \pm 0.00$ \\
\hline Salvigenin (31) & ND & $0.09 \pm 0.00$ \\
\hline Isothymusin (30) & ND & $0.12 \pm 0.00$ \\
\hline Genkwanin (32) & ND & $0.10 \pm 0.00$ \\
\hline Subtotal & 1.74 & 14.60 \\
\hline \multicolumn{3}{|c|}{ Flavanone aglycones } \\
\hline Eriodictyol (21) & $0.24 \pm 0.00$ & $0.69 \pm 0.02$ \\
\hline Naringenin (26) & ND & $0.54 \pm 0.01$ \\
\hline Subtotal & 0.24 & 1.23 \\
\hline Total flavone glycosides & 9.13 & 61.71 \\
\hline Total flavanone glycosides & 3.00 & 20.65 \\
\hline Total flavonoids glycosides & 12.13 & 82.36 \\
\hline Total flavonoids aglycones & 1.98 & 15.83 \\
\hline Total flavonoids & 14.11 & 98.19 \\
\hline Total phenolic compounds & 16.74 & 102.31 \\
\hline
\end{tabular}

${ }^{1}$ Averages \pm standard deviation were obtained from three different experiments. ${ }^{\text {a }}$ Expressed as arbutin equivalents; ${ }^{b}$ expressed as apigenin-7-O-glucoside equivalents; ${ }^{c}$ expressed as acacetin-7-O-glycoside equivalents; ${ }^{d}$ expressed as luteolin-7-O-glucoside equivalents; ${ }^{\mathrm{e}}$ expressed as eryodictyol-7-O-glucoside equivalents; ND—not detected. 
Significant diversities in the flavone and flavanone aglycone profiles of D. palmatum grown in all temperature conditions were observed. Common aglycones such as apigenin (27) and luteolin (24) were detected in both experimental groups; however, the amount of luteolin in the LT plants exceeded the same amount in D. palmatum cultivated in NT conditions by more than 10 times.

In addition, the presence of rare methoxylated flavone aglycones such as acacetin (29), isothymusin (30), salvigenin (31) and genkwanin (32) was revealed only in plants cultivated in LT conditions. The sum of flavone aglycones in this group $(14.6 \mathrm{mg} / \mathrm{g})$ significantly exceeded the amount of aglycone compounds in NT environments $(1.74 \mathrm{mg} / \mathrm{g})$. Flavanone eriodictyol (21) was detected in the NT group in quantities less than 2.9 times compared to plants cultivated in LT conditions, while naringenin (26) was revealed only in the latter experimental group. Therefore, plants under LT are characterized by an increased concentration of free aglycones, including polymethoxylated flavonoids.

The high amount of lipophilic flavonoid aglycones can be explained by their ecophysiological role, which includes providing plants with protection from abiotic stress signals [61]. The lipophilic nature of flavonoid aglycones limited their distribution in plants, which is in contrast to water-soluble flavonoid glycosides. As they usually accumulate on the leaf surface and are extruded through the cuticle, they are known as surface or external flavonoids. Flavonoid aglycones, especially in the highly methylated form, accumulate in the Lamiaceae family [62]. The early note that species of the Dracocephalum genus are unable to accumulate external flavonoids as aglycons should be revised [63]. Low temperatures are known to positively affect the accumulation of the cuticular leaf wax. This mechanism protects plant tissues from cold stress [64]. Lipophilic flavonoid aglycons (polyhydroxylated and polymethoxylated) covalently bind to cutin or associate with waxes $[65,66]$. Thus, the presence of polymethoxylated flavonoid aglycones suggests its vital role as the first site of plant defense against abiotic stresses, such as LT. Thus, exposing D. palmatum plants to HT or LT resulted in significant changes in the phenolic composition of its metabolome.

\subsection{Changes of Carbohydrates of D. palmatum during LT-Cultivation}

Carbohydrates of plants are key indicators of biochemical changes during temperature acclimation and the acquisition of cold tolerance [67]. Various forms of soluble sugars are involved in physiological reactions to temperature stress: simple sugars such as the mono- and oligosaccharides and polymeric components such as polysaccharides. Known data about soluble sugars of Lamiaceae display a wide distribution of glucose and sucrose as well as the raffinose family oligosaccharides (RFO) [68]. Application of RP-HPLC-MS in selected ion monitoring mode with negative ionization allowed detecting four carbohydrates in samples of D. palmatum (Figure 3).

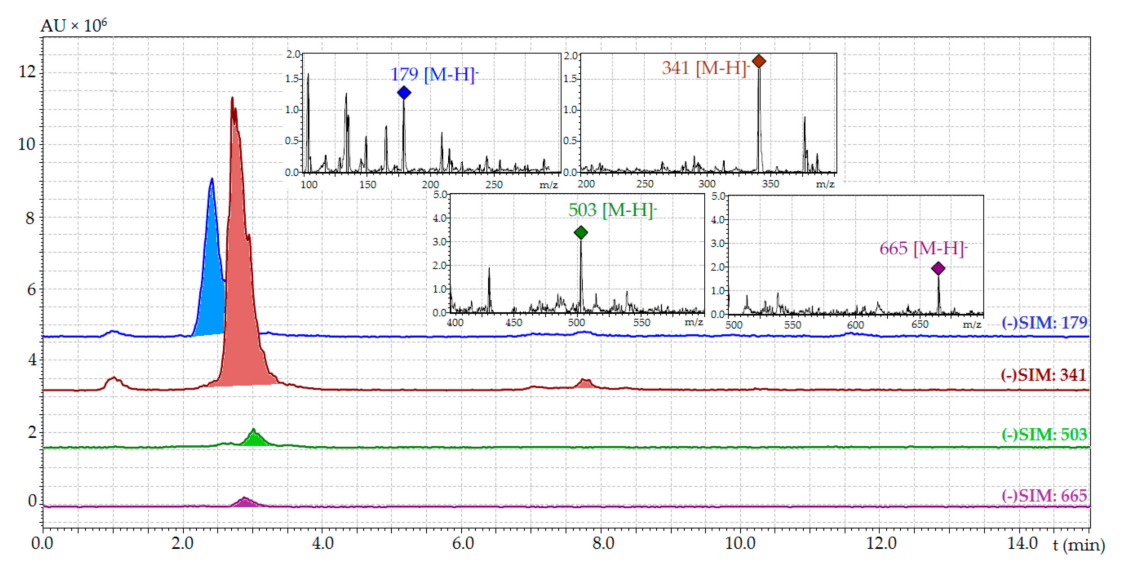

Figure 3. RP-HPLC-MS chromatograms in selected ion monitoring mode (SIM, negative ionization) of free sugars fraction of $D$. palmatum herb (low-temperature sample). SIM with following $m / z$ value used: 179 for glucose, 341 for sucrose, 503 for raffinose, 665 for stachyose. On cuts, mass spectra of corresponding compounds; $\mathrm{AU}$, absorbance units. 
Components were identified as glucose, sucrose ( $\alpha$-D-glucopyranosyl- $(1 \rightarrow 2)-\beta$-D-fructofuranoside), raffinose ( $\alpha$-D-galactopyranosyl-( $1 \rightarrow 6)-\alpha$-D-glucopyranosyl-( $1 \rightarrow 2)-\beta$-D-fructofuranoside) and stachyose ( $\alpha$-D-galactopyranosyl-( $1 \rightarrow 6)-\alpha$-D-galactopyranosyl-( $1 \rightarrow 6)$ - $\alpha$-D-glucopyranosyl-( $1 \rightarrow 2)-\beta$-D-fructofuranoside) using HPLC and ESI-MS-data compared to standards (Table 6). Sucrose accumulated to a much higher extent at all temperatures of D. palmatum cultivation $(35.54-169.21 \mathrm{mg} / \mathrm{g}$ ) (Table 6). The concentrations of raffinose $(0.87-9.36 \mathrm{mg} / \mathrm{g})$ and stachyose $(1.72-38.95 \mathrm{mg} / \mathrm{g})$ were lower than glucose $(16.86-26.39 \mathrm{mg} / \mathrm{g})$.

Table 6. HPLC parameters, electrospray ionization mass spectrometry (ESI-MS) data and the content of simple sugars $(\mathrm{mg} / \mathrm{g} \mathrm{DW} \pm \mathrm{SD})$ in $D$. palmatum herb under different temperatures of cultivation.

\begin{tabular}{ccccc}
\hline & & & \multicolumn{2}{c}{ Content $(\mathbf{m g} / \mathbf{g})^{\mathbf{1}}$} \\
\cline { 4 - 5 } Compound & $\mathbf{t}_{\mathbf{R}}(\mathbf{m i n})$ & ESI-MS $(\mathbf{m} / \mathbf{z})$ & \multicolumn{2}{c}{ Temperature $\left({ }^{\circ} \mathbf{C}\right)$} \\
\cline { 3 - 5 } & & & $\mathbf{2 0}$ & $\mathbf{1}$ \\
\cline { 4 - 5 } & 2.38 & $179[\mathrm{M}-\mathrm{H}]^{-}$ & $16.86 \pm 0.32$ & $26.39 \pm 0.52$ \\
Glucose & 2.73 & $341[\mathrm{M}-\mathrm{H}]^{-}$ & $35.54 \pm 0.78$ & $169.21 \pm 3.72$ \\
Sucrose & 2.89 & $665[\mathrm{M}-\mathrm{H}]^{-}$ & $1.72 \pm 0.03$ & $38.95 \pm 0.82$ \\
Stachyose & 3.04 & $503[\mathrm{M}-\mathrm{H}]^{-}$ & $0.87 \pm 0.02$ & $9.36 \pm 0.18$ \\
Raffinose & & & 54.99 & 243.91 \\
Total content & & & \\
\hline
\end{tabular}

${ }^{1}$ Averages \pm standard deviations were obtained from three different experiments.

The levels of glucose and oligosaccharides in D. palmatum gradually increased during the low-temperature experiment. Total concentration of mono- and oligosaccharides in D. palmatum increased from $54.99 \mathrm{mg} / \mathrm{g}$ in group with NT cultivation to $243.91 \mathrm{mg} / \mathrm{g}$ in the group with a LT of cultivation. The differences between separate sugar amounts in the $20^{\circ} \mathrm{C}$ and $1{ }^{\circ} \mathrm{C}$ groups were 1.6-, 4.8-, 10.8- and 22.6-fold for glucose, sucrose, raffinose and stachyose, respectively.

Previous studies have demonstrated that soluble low-molecular weight sugars play multiple roles in LT tolerance of plants. Concentrations of glucose and sucrose may increase several fold during exposure to LT [69]. The accumulation of sucrose in cane sugar supports their function as an osmoprotectant that stabilizes cellular membranes and maintains turgor [70]. The RFOs (raffinose, stachyose) are especially associated with cold hardiness, LT and dormancy [71]. Reaction of the simple sugar profile of D. palmatum LT cultivation was typical for cold-tolerant crops: increases in mono- and oligosaccharide levels were observed. No dramatic changes occurred in D. palmatum sugars after HT cultivation $\left(35^{\circ} \mathrm{C}\right)$.

Cold acclimation of plants also induced changes both in non-structural or reserve polysaccharides as starch or inulin and cell wall polysaccharides like pectin and pectin-associated polymers [72]. For characterization of polymeric sugars of the herb D. palmatum, the high-molecular polysaccharides were isolated by ethanol precipitation, followed by dialysis to yield $2.29 \%$ and $9.86 \%$ (referring to the dried herb of the $20^{\circ} \mathrm{C}$ and $1{ }^{\circ} \mathrm{C}$ plant groups, respectively) raw water-soluble polysaccharides (RWSP) (Table 7).

The dialyzed RWSP contained a high amount of uronic acid, which increased from 43.57 in the $20{ }^{\circ} \mathrm{C}$ group to $46.16 \%$ in the $1{ }^{\circ} \mathrm{C}$ group and a low concentration of protein components $(2.61-2.75 \%)$. All samples of RWSP gave a positive reaction with iodine and Yariv reagent, demonstrating the presence of starch and arabinogalactan-protein complexes, respectively. No reaction with either resorcinol and Fehling's reagent indicated the absence of inulin and polymeric mannans. The polysaccharide fractions were composed of galacturonic acid, galactose, glucose and arabinose as main sugars with ratios of 4.1:2.6:1.4:1 and 4.4:2.7:1.0:1 for plants grown at NT and LT, respectively. Quantitatively minor components of RWSP were mannose, rhamnose, glucuronic acid and fucose and trace monomers such as xylose and ribose. Thus, the polysaccharide composition of $D$. palmatum seems to be composed of a mixture of starch, arabinogalactans and/or arabinogalactan-protein complexes and pectic components with high uronic amount. 
Table 7. Yield of raw water soluble polysaccharide (RWSP) of D. palmatum herb under different temperatures of cultivation, their general characteristics and monosaccharide compositions.

\begin{tabular}{|c|c|c|}
\hline \multirow{2}{*}{ Parameter } & \multicolumn{2}{|c|}{ Temperature $\left({ }^{\circ} \mathrm{C}\right)$} \\
\hline & 20 & 1 \\
\hline RWSP yield (\%) ${ }^{a}$ & $2.29 \pm 0.04^{c}$ & $9.86 \pm 0.20^{c}$ \\
\hline \multicolumn{3}{|c|}{ RWSP general characteristics } \\
\hline Protein content, $\% \mathrm{~b}$ & $2.61 \pm 0.07^{c}$ & $2.75 \pm 0.09^{c}$ \\
\hline Uronic acids, $\% \mathrm{~b}$ & $43.57 \pm 1.01^{\mathrm{c}}$ & $46.16 \pm 1.14^{\mathrm{c}}$ \\
\hline Reaction with $\mathrm{I}_{2}$ (starch) & positive & positive \\
\hline Reaction with resorcinol (inulin) & negative & negative \\
\hline Reaction with Yariv's reagent (AGP-complexes) & positive & positive \\
\hline Reaction with Fehling's reagent (mannans) & negative & negative \\
\hline \multicolumn{3}{|c|}{ RWSP monosaccharide composition (mol \%) } \\
\hline Ara & 10.1 & 10.2 \\
\hline Gal & 26.1 & 27.7 \\
\hline Glc & 14.4 & 10.2 \\
\hline Fuc & 0.1 & 0.1 \\
\hline Man & 4.3 & 4.0 \\
\hline Rha & 1.9 & 1.7 \\
\hline Rib & Tr. ${ }^{d}$ & Tr. ${ }^{d}$ \\
\hline Xyl & Tr. ${ }^{d}$ & Tr. ${ }^{d}$ \\
\hline GalA & 41.2 & 44.6 \\
\hline GlcA & 1.8 & 1.4 \\
\hline
\end{tabular}

a Percentage of dry plant weight $\pm \mathrm{SD} ;{ }^{\mathrm{b}}$ Percentage of dry RWSP weight $\pm \mathrm{SD} ;{ }^{\mathrm{c}}$ Averages \pm standard deviations were obtained from three different experiments; ${ }^{\mathrm{d}}$ Tr., traces $(<0.1 \mathrm{~mol} \%)$.

Regarding monosaccharide composition of RWSP samples, two evident changes observed with the polysaccharide complex of D. palmatum growing at LT should be mentioned: (i) the amount of glucose in RWSP increased after cultivation temperature increased; and (ii) the amount of galacturonic acid, galactose and arabinose in RWSP increased after cultivation temperature decreased. The first event may be caused by the influence of the main plant glucose-containing polymer (starch), whose amount typically declines during exposure to LTs due to hydrolysis [73]. Cold-induced starch degradation was supported many times for various species as a process involved in the freezing tolerance enhancement of plants during an early phase of cold acclimation [74]. The cumulative effect of LT on galacturonic acid as a principal component of pectin and galactose and arabinose as monomers of satellite arabinogalactans was also previously discussed. Pectins appear to be a key element of the plant response to cold stress as shown by a number of studies on various species [75]. In Pisum sativum L., cold acclimation was accompanied by an increase in galacturonan and highly branched rhamnogalacturonan with branched and unbranched arabinans and galactans. The increased cold tolerance might be related to increased synthesis of arabinan and galactan side chains and galacturonan, which may act as a gelling component and a cold protectant [76].

\subsection{Changes of Malondialdehyde, Antioxidant Enzymes and Antioxidant Potential of D. palmatum during LT-Cultivation}

Low temperature not only caused various phenotypic changes but also initiates cellular damages reflected on increased electrolyte leakage and misbalance in reactive oxygen species (ROS) level and antioxidant content. Malondialdehyde (MDA) served as an indicator of cell membrane injury, elevated concentration of ROS and lipid peroxidative processes [77]. The level of MDA in NT plants was $92.74 \mathrm{nM} / \mathrm{g}$ fresh weight in opposite to LT plants with a value $197.02 \mathrm{nM} / \mathrm{g}$ fresh weight (Table 8). These results verified a significant raise in MDA content in leaf tissues after LT treatment, signifying that cold stress affected oxidative lipid injury. For scavenging of ROS, plants have a specific antioxidant 
mechanisms included enzymatic (superoxide dismutase, catalase and other) and non-enzymatic antioxidants [78]. Superoxide dismutase (SOD) plays a determinant role in protection against the toxic effects of oxidative stress by scavenging superoxide radicals and promoting their conversion into oxygen and hydrogen peroxide [79]. Catalase is an enzyme that functions in $\mathrm{H}_{2} \mathrm{O}_{2}$ degradation, which maintains hydrogen peroxide homeostasis in plants [80]. We measured the activities of two enzymatic antioxidants as superoxide dismutase and catalase in D. palmatum leaf tissue of NT an LT groups. The results indicated that the low temperature induced a significant increase of activity of both enzymes in 4.6 and 1.7 times comparing with NT plants (respectively, for SOD and catalase). The rising activity of antioxidant enzymes is a plant response to high level of the ROS, resulting in protection of cell membranes from increased MDA to accommodate LT stress [81].

The antioxidant properties of $D$. palmatum extracts were also analyzed by plenty methods both single-electron transfer (SET) and combination of SET with hydrogen-atom transfer techniques. To the latter methods total antioxidant capacity, DPPH ${ }^{\bullet}$ (2,2-diphenyl-1-picrylhydrazyl) and ABTS ${ }^{\bullet+}$ (2,2'-azino-bis(3-ethylbenzthiazoline-6-sulfonic acid) scavenging tests were related and successfully performed (Table 8). In turn among SET methods superoxide $\left(\mathrm{O}_{2}{ }^{\bullet-}\right)$ and bromine $\left(\mathrm{Br}^{\bullet}\right)$ radicals scavenging assays; nitric oxide (NO) and hydrogen peroxide $\left(\mathrm{H}_{2} \mathrm{O}_{2}\right)$ inactivating tests and ferrous (II) ion $\left(\mathrm{Fe}^{2+}\right)$ chelating assay were applied. In addition, all methods mentioned above were employed for evaluation of antioxidant potential of luteolin-7-O-glucoside, the dominant compound of D. palmatum herb with known property to prevent oxidation [82].

The total antioxidant capacity varied significantly in plant extracts and ranged from $280.98 \mathrm{mg} / \mathrm{g}$ (NT) to $682.26 \mathrm{mg} / \mathrm{g}$ (LT) (Table 8). In the DPPH ${ }^{\bullet}$ and $\mathrm{ABTS}^{\bullet+}$ assays, the LT plants demonstrated high efficiency in the scavenging of free radicals $\left(\mathrm{IC}_{50} 11.40\right.$ and $5.69 \mu \mathrm{g} / \mathrm{mL}$, respectively).

Table 8. Malondialdehyde (MDA) content, superoxide dismutase (SOD) and catalase activities of $D$. palmatum leaves and antioxidant activity of D. palmatum extracts obtained from the herb grown under different temperatures of cultivation and luteolin-7-O-glucoside as a reference compound ${ }^{\mathrm{a}, \mathrm{b}}$.

\begin{tabular}{|c|c|c|c|}
\hline \multirow{2}{*}{ Parameter } & \multirow{2}{*}{ Luteolin-7-O-Glucoside } & \multicolumn{2}{|c|}{ Temperature $\left({ }^{\circ} \mathrm{C}\right)$} \\
\hline & & 20 & 1 \\
\hline MDA content $(\mathrm{nM} / \mathrm{g}) \mathrm{FW}$ & - & $92.74 \pm 7.41$ & $197.02 \pm 15.76$ \\
\hline SOD activity $(\mathrm{U} / \mathrm{g} \cdot \mathrm{min}) \mathrm{FW}$ & - & $57.90 \pm 5.21$ & $264.32 \pm 12.35$ \\
\hline Catalase activity $(\mathrm{U} / \mathrm{g} \cdot \mathrm{min}) \mathrm{FW}$ & - & $0.93 \pm 0.06$ & $1.53 \pm 0.12$ \\
\hline $\begin{array}{l}\text { Total antioxidant capacity (mg-eq). } \\
\text { luteolin-7-O-glucoside/g }\end{array}$ & 1000 iii & $280.98 \pm 8.99^{\mathrm{i}}$ & $682.26 \pm 21.15^{\mathrm{ii}, \mathrm{iii}}$ \\
\hline $\mathrm{DPPH}^{\bullet}$-radical scavenging activity, $\mathrm{IC}_{50}(\mu \mathrm{g} / \mathrm{mL})$ & $16.97 \pm 0.34^{\mathrm{iv}, \mathrm{v}}$ & $33.28 \pm 0.73$ vi & $11.40 \pm 0.24{ }^{\text {iv }}$ \\
\hline $\mathrm{ABTS}^{\bullet+}$-radical scavenging activity, $\mathrm{IC}_{50}(\mu \mathrm{g} / \mathrm{mL})$ & $9.86 \pm 0.19$ vii,viii & $14.62 \pm 0.31$ viii & $5.69 \pm 0.11$ vii \\
\hline $\mathrm{O}_{2}^{\bullet-}$-radical scavenging activity, $\mathrm{IC}_{50}(\mu \mathrm{g} / \mathrm{mL})$ & $14.92 \pm 0.43^{\mathrm{ix}, \mathrm{x}}$ & $18.36 \pm 0.56^{x}$ & $9.21 \pm 0.21^{\mathrm{ix}}$ \\
\hline $\begin{array}{l}\mathrm{Br}{ }^{\bullet} \text {-radical scavenging activity (mg-eq). } \\
\text { luteolin-7-O-glucoside/g }\end{array}$ & 1000 xii & $150.19 \pm 1.95^{\mathrm{xi}}$ & $799.63 \pm 11.19$ xii \\
\hline NO inactivating activity, $\mathrm{IC}_{50}(\mu \mathrm{g} / \mathrm{mL})$ & $>100$ & $37.92 \pm 1.59$ & $21.37 \pm 0.85^{\text {xiii }}$ \\
\hline $\mathrm{H}_{2} \mathrm{O}_{2}$ inactivating activity $(\mathrm{mM} / \mathrm{g})$ & $0.53 \pm 0.02^{\text {xiv }}$ & $1.56 \pm 0.04$ & $2.75 \pm 0.06^{\mathrm{xv}}$ \\
\hline $\mathrm{Fe}^{2+}$-chelating activity $(\mu \mathrm{M}) \mathrm{Fe}^{2+} / \mathrm{g}$ & $106.12 \pm 3.18^{\mathrm{xvi}}$ & $142.84 \pm 4.42^{\mathrm{xvi}, \mathrm{xvii}}$ & $206.11 \pm 4.78^{\text {xviii }}$ \\
\hline
\end{tabular}

The plants cultivated in NT conditions demonstrated less pronounced scavenging activity to inactivate $\mathrm{DPPH}^{\bullet}$ and $\mathrm{ABTS}^{\bullet+}$ free radicals. The scavenging value against superoxide radicals was highest in the group cultivated in LT environments ( IC $_{50} 9.21 \mu \mathrm{g} / \mathrm{mL}$ ). The efficiency of luteolin-7-O-glucoside in this assay was lower $\left(\mathrm{IC}_{50} 14.92 \mu \mathrm{g} / \mathrm{mL}\right)$. The extract obtained from the herb grown in LT manifested significant scavenging activity of NO molecules $(21.37 \mu \mathrm{g} / \mathrm{mL})$. The herb extracts from plants cultivated in NT conditions demonstrated less pronounced scavenging activity ( $\mathrm{IC}_{50} 37.92 \mu \mathrm{g} / \mathrm{mL}$, respectively). In addition, the activity of the LT group in the $\mathrm{H}_{2} \mathrm{O}_{2}$ inactivating assay and $\mathrm{Fe}^{2+}$-chelating activity assay was characterized as very high in both methods, opposite of the 
low activity of luteolin-7-O-glucoside. It should be noted that herbal extract cultivated in the LT group was the most active antioxidant in all assays. Early information about the quantitative levels in the experimental groups allowed us to associate the significant antioxidant potential of this extract with the highest total phenolics levels.

Previously, the antioxidant properties of several Dracocephalum extractions were analysed. Thus, methanol extract from the aerial parts of $D$. moldavica revealed high efficiency in the scavenging of $\mathrm{DPPH}^{\bullet}, \mathrm{ABTS}^{\bullet+}$ and superoxide anion radicals $\left(\mathrm{IC}_{50} 23.10,8.0\right.$ and $445.5 \mu \mathrm{g} / \mathrm{mL}$, respectively). The total phenolic value was $289.55 \mathrm{mg} / \mathrm{g}$ of dry extract, and rosmarinic acid was the major polyphenol (107.11 mg/g of dry extract) [83]. Luteolin-7-O-glucoside isolated from whole plant D. tanguticum exhibited the highest antioxidant effect in $\mathrm{DPPH}^{\bullet}\left(\mathrm{IC}_{50} 3.94 \mu \mathrm{M}\right), \mathrm{ABTS}^{\bullet+}\left(\mathrm{IC}_{50} 56.46 \mu \mathrm{M}\right)$ and ferrous ions radicals $\left(\mathrm{IC}_{50} 1.10 \mathrm{mM}\right.$ ) [84]. The methanol extract of $D$. heterophyllum demonstrated high efficiency in the scavenging of $\mathrm{DPPH}^{\bullet}$ radicals $\left(\mathrm{IC}_{50} 37.0 \mu \mathrm{g} / \mathrm{mL}\right.$ ) [85]. The total phenolic amount of the D. kotschyi methanol extract from leaves was $175.6 \mathrm{mg} / \mathrm{g}$ and $\mathrm{DPPH}^{\bullet}$ scavenging capacity of the same extract was $88.99 \%$ [86]. The methanol extract from the aerial portion of $D$. polychaetum revealed effective scavenging of $\mathrm{DPPH}^{\bullet}$ radicals $\left(\mathrm{IC}_{50} 5.6 \mathrm{mg} / \mathrm{mL}\right.$ ) [87].

Bioactivity of D. palmatum extracts was dependent from cultivation temperature level. In particular, the antiradical potential against various particles, including neutral 2,2-diphenyl-1-picrylhydrazyl radical and bromine radical, and charged 2,2'-azino-bis(3-ethylbenzthiazoline-6-sulfonic acid) cation-radical and superoxide anion-radical was the highest for the samples cultivated in cold-temperature condition. Inactivating power of the same plant extract in relation nitric (II) oxide and hydrogen peroxide molecules as well as $\mathrm{Fe}^{2+}$ chelating ability significantly exceeded the results obtained in other experimental groups and was similar to or exceeded the activity of the reference antioxidant, luteolin-7-O-glucoside.

\section{Materials and Methods}

\subsection{Chemicals}

The following chemicals were purchased from Biosupplies Australia Ply Ltd. (Victoria, Australia): Yariv reagent kit (Cat. No. 100-4); Extrasynthese (Lyon, France): acacetin-7-O-rutinoside (linarin; Cat. No. 1169, $\geq 98.5 \%$ ); apigenin-7-O-rutinoside (isorhoifolin; Cat. No. 1121, $\geq 98.5 \%$ ); 5-O-caffeoyl quinic acid (neochlorogenic acid; Cat. No. 4961, $\geq 99 \%$ ); 3-O-caffeoylquinic acid (chlorogenic acid; Cat. No. 4991, $\geq 99 \%$ ); caffeic acid (Cat. No. 6034, $\geq 99 \%$ ); luteolin-7-O-glucoside (cynaroside; Cat. No. 1126, $\geq 98 \%$ ); luteolin-4'-O-glucoside (Cat. No. 1083, $\geq 95 \%$ ); rosmarinic acid (Cat. No. 4957, $\geq 99 \%$ ); ChemFaces (Wuhan, China): acacetin-7-O-glucoside (tilianin; Cat. No. CFN92764, $\geq 95 \%$ ); chrysoeriol (Cat. No. CFN98785, $\geq 95 \%$ ); isothymusin (Cat. No. CFN97562, $\geq 95 \%$ ); salvigenin (Cat. No. CFN99883, $\geq 95 \%$ ); raffinose (Cat. No. CFN90425, $\geq 98 \%$ ); stachyose (Cat. No. CFN90424, $\geq 98 \%$ ); Santa Cruz Biotechnology, Inc. (Dallas, TX, USA): $\beta$-phellandrene (Cat. No. sc-477582, $\geq 98 \%$ ); Sigma-Aldrich (St. Louis, MO, USA): acacetin (Cat. No. 00017, $\geq 97 \%$ ); apigenin (Cat. No. 10798, $\geq 95 \%$ ); apigenin-7-O-glucoside (cosmosiin, Cat. No. 44692, $\geq 97 \%$ ); arabinose (Cat. No. A3256, $\geq 99 \%$ ); arbutin (Cat. No. A4256, $\geq 98 \%$ ); 2,2'-azino-bis(3-ethylbenzothiazoline-6-sulfonic acid) diammonium salt (Cat. No. A1888, $\geq 98 \%$ ); bornyl acetate (Cat. No. 45855, $\geq 99 \%$ ); camphene (Cat. No. 456055, $\geq 95 \%$ ); $\beta$-caryophyllene (Cat. No. 75541, $\geq 98.5 \%$ ); caryophyllene oxide (Cat. No. 91034, $\geq 99 \%$ ); 1,8-cineol (Cat. No. 29210, $\geq 99 \%$ ); $p$-cymene (Cat. No. 30039, $\geq 99.5 \%$ ); $p$-cumenol (Cat. No. 175404, $\geq 98 \%$ ); cuminaldehyde (Cat. No. 16679, $\geq 97 \%$ ); 2,2-diphenyl-1-picrylhydrazyl (Cat. No. D9132); eriodictyol (Cat. No. 74565, $\geq 95 \%$ ); eriodictyol-7-O-rutinoside (eriocitrin; Cat. No. 45714, $\geq 98 \%$ ); eriodictyol-7-O-glucoside (Cat. No. 19474, $\geq 99 \%$ ); Fehling's reagent I (Cat. No. 36018); fucose (Cat. No. F8150, $\geq 98 \%$ ); galactose (Cat. No. G0750, $\geq 99 \%$ ); galacturonic acid monohydrate (Cat. No. 48280, $\geq 97 \%$ ); genkwanin (Cat. No. SMB00422, $\geq 98 \%$ ); glucose (Cat. No. G8270, $\geq 99.5 \%$ ); glucuronic acid (Cat. No. G5269, $\geq 98 \%$ ); isoamyl acetate (Cat. No. 79857, $\geq 99.7 \%$ ); limonene (Cat. No. 62118, $\geq 99 \%$ ); linalool (Cat. No. 51782, $\geq 99 \%$ ); lithium 
perchlorate (Cat. No. 431567, $\geq 99.99 \%$ ); luteolin (Cat. No. L9283, $\geq 98 \%$ ); luteolin-7-O-rutinoside (scolymoside; Cat. No. SMB00200, $\geq 95 \%$ ); mannose (Cat. No. M8574, $\geq 99 \%$ ); $\beta$-myrcene (Cat. No. W276200, $\geq 95 \%$ ); myrtenyl acetate (Cat. No. 80699, $\geq 95 \%$ ); naringenin (Cat. No. N58ra93, $\geq 95 \%$ ); naringenin-7-O-glucoside (prunin; Cat. No. SMB00076, $\geq 95 \%$ ); $\alpha$-pinene (Cat. No. 80605, $\geq 98.5 \%$ ); $\beta$-pinene (Cat. No. 80609, $\geq 98.5 \%$ ); trans-pinocarveol (Cat. No. 80613, $\geq 96 \%$ ); perchloric acid (Cat. No. 311421, $\geq 70 \%, 99.999 \%$ trace metals basis); resorcinol (Cat. No. 398047, $\geq 99 \%$ ); ribose (Cat. No. R7500, $\geq 99 \%$ ); rhamnose (Cat. No. W373011, $\geq 99 \%$ ); sabinene (Cat. No. 275166, $\geq 99 \%$ ); sucrose (Cat. No. S9378, $\geq 99.5 \%$ ); $\gamma$-terpinene (Cat. No. 86476, $\geq 98.5 \%$ ); terpinene-4-ol (Cat. No. 49598, $\geq 95 \%$ ); and xylose (Cat. No. X1500, $\geq 99 \%$ ). Luteolin-7,4'-di-O-rutinoside (dracopalmaside) and luteolin-7-O-rutinoside-4'-O-glucoside (cynarotriside) were isolated previously from D. palmatum [9].

\subsection{Plant Material, Growth Conditions, and Stress Treatments}

D. palmatum were grown from authenticated seeds obtained from Tsitsin's Main Botanical Garden of the Russian Academy of Science (Moscow, Russia). Seeds were collected from the Republic Yakutia, Kobyaiskii region, village Kitchan (year of collection 1991). Seeds were sterilized by incubation for $1 \mathrm{~min}$ in $75 \%$ ethanol and then washed thoroughly with sterile water. The seeds were germinated in soil in peat pots at $20{ }^{\circ} \mathrm{C}\left(16 \mathrm{~h}\right.$ light at photon flux $135 \mu \mathrm{mol} \mathrm{m}{ }^{-2} \mathrm{~s}^{-1} / 8 \mathrm{~h}$ dark at $\left.16{ }^{\circ} \mathrm{C}\right)$. Seedlings at the age of two-month old were subjected to environmental stress. Plants were divided into two groups, one group continued to grow in normal temperature conditions $\left(20^{\circ} \mathrm{C}\right)$. For low temperature treatments, seedlings were transferred to a temperature of $1{ }^{\circ} \mathrm{C}$ in an artificial climate box for 20 days. The following light and photoperiodic conditions have been used for seedlings growing: $16 \mathrm{~h}$ light at $20^{\circ} \mathrm{C}$ (or $1^{\circ} \mathrm{C}$ ) and photon flux $490 \mu \mathrm{mol} \mathrm{m}{ }^{-2} \mathrm{~s}^{-1} / 8 \mathrm{~h}$ dark at $20^{\circ} \mathrm{C}\left(\right.$ or $1{ }^{\circ} \mathrm{C}$ ). The herbs were collected after 20 days of the environmental stress treatment. The experimental samples were immediately frozen in liquid nitrogen and stored at $-80^{\circ} \mathrm{C}$ until use for analysis of photosynthetic pigments, malondialdehyde and enzyme activity. A part of fresh material was shade dried at room temperature before analytical assays (phenolic compounds, free sugars), isolation procedures (fatty acids, essential oil, polysaccharides) and bioactivity determination (dry extracts).

\subsection{Electrolyte Leakage}

Electrolyte leakage was measured following method of Campos et al. [88]. Twenty freshly cut leaf discs $\left(0.5 \mathrm{~cm}^{2}\right.$ each) were rinsed 3 times $(2-3 \mathrm{~min})$ with demineralized water and subsequently floated at $4{ }^{\circ} \mathrm{C}$ on $10 \mathrm{~mL}$ of demineralized water in the dark in the growth chamber. The conductivity of the suspending solution was measured after $24 \mathrm{~h}$ using an electrical conductivity analyzer (Expert-002-2-6n; Econics-Expert Co., Ltd., Moscow, Russia) before and after autoclaving at $120{ }^{\circ} \mathrm{C}$ for $30 \mathrm{~min}$ to release the total electrolytes. Electrolyte leakage was calculated as a percentage of total electrolytes. The results were presented as the mean values $\pm \mathrm{SD}$ (standard deviations) of three replicates.

\subsection{Photosynthetic Pigments Analysis}

Photosynthetic pigments (chlorophylls, carotenes, pheophytins) were determined using multi-wavelength spectrophotometric method. Frozen weighed plant leaves $(0.5 \mathrm{~g})$ were homogenized under liquid nitrogen and an aliquot of $2 \mathrm{~g}$ was weighed into a 50-mL centrifuge tube with $10 \mathrm{~mL}$ of acetone/water mixture (4:1). After vortexing (1 min), mixing, and shaking for $30 \mathrm{~min}$, samples were centrifuged for $15 \mathrm{~min}$ at $3000 \times g$ at room temperature. The procedure of acetone/water extraction was repeated twice and organic fractions were combined in a volumetric flask $(50 \mathrm{~mL})$. The final volume of organic extract was reached to $50 \mathrm{~mL}$ by acetone/water mixture (4:1). The absorbance of the organic extract was measured using SF-2000 UV-Vis-spectrophotometer (OKB Specter; St. Petersburg, Russia) in a $1 \mathrm{~cm}$ quartz cuvette at 470/646.8/663.2 nm (chlorophylls, carotenes) and 536/666 nm (pheophytins) blanked with acetone/water mixture (4:1). Pigment concentrations were calculated using corresponding absorption coefficients [89,90]. The results were expressed in fresh weight basis and were presented as the mean values $\pm \mathrm{SD}$ (standard deviations) of three replicates. 


\subsection{Chlorophyll Fluorescence and Carbon Assimilation Rate Measurement}

Chlorophyll fluorescence was measured on the upper leaf surfaces by PAM fluorometer Junior PAM (Heinz Walz GmbH, Effeltrich, Germany). The following fluorescence parameters were measured: minimal fluorescence in the dark-adapted state $\left(\mathrm{F}_{0}\right)$ and the maximal fluorescence in the dark adapted state $\left(\mathrm{F}_{\mathrm{m}}\right)$. Maximal quantum yield of PSII photochemistry $\left(\mathrm{F}_{\mathrm{v}} / \mathrm{F}_{\mathrm{m}}\right)$ was calculated according to equation: $\mathrm{F}_{\mathrm{v}} / \mathrm{F}_{\mathrm{m}}=\left(\mathrm{F}_{\mathrm{m}}-\mathrm{F}_{0}\right) / \mathrm{F}_{\mathrm{m}}$. The parameter of the carbon assimilation rate $\left(\right.$ as $\left.\mu \mathrm{M} \mathrm{CO}_{2} / \mathrm{m}^{2} \cdot \mathrm{s}\right)$ was analyzed using infrared gas analyzer LCpro+ Portable Gas Exchange System (ADC BioScientific Ltd., Hertfordshire, UK) coupled with Small Leaf Chamber. The results were presented as the mean values $\pm \mathrm{SD}$ (standard deviations) of ten replicates.

\subsection{Fatty Acids Analysis}

Fatty acids were extracted using a modified Folch method [91] following by the esterification into fatty acids methyl esters (FAMEs) [92]. The pulverized dried herb $(0.1 \mathrm{~kg})$ was extracted at $70{ }^{\circ} \mathrm{C}$ for $10 \mathrm{~h}$ by Soxhlet extractor with $500 \mathrm{~mL}$ of chloroform-methanol (2:1) mixture. The solvent was evaporated to dryness at $35{ }^{\circ} \mathrm{C}$ and to yield the fatty acid fraction (FAF). Samples of FAF (0.1 g) were dissolved in $4 \mathrm{~mL}$ of $0.5 \mathrm{~N}$ sodium hydroxide solution in methanol and boiled under reflux for $60 \mathrm{~min}$. After saponification, $3 \mathrm{~mL}$ of boron trifluoride methanolic solution $(14 \%, v / v)$ was added and the solution boiled for $15 \mathrm{~min}$ following by hexane $(6 \mathrm{~mL})$ addition and heating under reflux (10 $\mathrm{min})$. Then saturated sodium chloride $(1 \mathrm{~mL})$ was added, vortexed $(10 \mathrm{~s})$ and centrifuged at $6000 \mathrm{rpm}$ (15 $\mathrm{min})$. The upper hexane layer was removed, concentrated $\left(\mathrm{N}_{2}\right)$, and the resultant residue was dissolved in hexane $(200 \mu \mathrm{L})$ before gas chromatography-mass spectrometry (GC-MS) analysis.

The GC-MS system was consisted of an Agilent $6890 \mathrm{~N}$ gas chromatograph and an Agilent Technologies $5973 \mathrm{~N}$ mass selective/quadrupole detector (Agilent Technologies Inc., Santa Clara, CA, USA). A capillary column HP-INNOWax with a length of $30 \mathrm{~m}$, inner diameter of $0.25 \mathrm{~mm}$, and film thickness of $0.5 \mu \mathrm{m}$ was used for separation (Agilent Technologies Inc., Santa Clara, CA, USA) with helium at a $25 \mathrm{~mL} / \mathrm{min}$ as a carrier gas. The temperature was $40{ }^{\circ} \mathrm{C}$ after injection then programmed at $2{ }^{\circ} \mathrm{C} / \mathrm{min}$ to $300{ }^{\circ} \mathrm{C}$, and maintained at that temperature for $45 \mathrm{~min}$. A solvent delay of $9 \mathrm{~min}$ was set before MS acquisition began. The transfer line from GC column to MS was set to $180{ }^{\circ} \mathrm{C}$, the source $230{ }^{\circ} \mathrm{C}$, and the quadrupole $150{ }^{\circ} \mathrm{C}$. MS detector was done by electron ionization at $70 \mathrm{eV}$, with a scan range of 30 a.m.u. to 700 a.m.u. (1 scan/s). Compounds were identified by using online NIST 05 and Wiley-7th library spectra, published MS data and analytical standards parameters of available FAMEs. Stock standard solutions of available FAMEs were prepares by dissolving FAME mixture (Supelco-37 mixture $\mathrm{C}_{4}-\mathrm{C}_{24}$, Sigma-Aldrich, St. Louis, MO, USA) in hexane at a concentration $0.2 \mathrm{mg} / \mathrm{mL}$. Tridecanoic acid was used as the internal standard and was dissolved in hexane at concentration $0.5 \mathrm{mg} / \mathrm{mL}$. The relative content of each FAME was calculated by normalization of the obtained total ion current peak areas as the percentages of total fatty acids.

\subsection{Essential Oil Analysis}

The pulverized dried herb (300 g) was placed in a $2000 \mathrm{~mL}$ round-bottom flask along with $600 \mathrm{~mL}$ distilled water and subjected to Clevenger hydrodistillation for $2.5 \mathrm{~h}$. The oil was extracted from the distillate with hexane and then dried over anhydrous sodium sulfate. The solvent was evaporated using rotary evaporator gave the essential oil. The aliquot of essential oil $(10 \mu \mathrm{L})$ was dissolved in hexane $(500 \mu \mathrm{L})$ before gas chromatography-mass spectrometry (GC-MS) analysis.

The GC-MS system was consisted of an Agilent $6890 \mathrm{~N}$ gas chromatograph and an Agilent Technologies $5973 \mathrm{~N}$ mass selective/quadrupole detector (Agilent Technologies Inc., Santa Clara, CA, USA). A capillary column HP-5MS with a length of $30 \mathrm{~m}$, inner diameter of $0.25 \mathrm{~mm}$, film thickness of $0.5 \mu \mathrm{m}$ and 5\% diphenyl- and 95\% dimethylpolysiloxane as stationary phase was used for separation (Agilent Technologies Inc., Santa Clara, CA, USA) with helium at a $1 \mathrm{~mL} / \mathrm{min}$ as a carrier gas. The temperature was $150{ }^{\circ} \mathrm{C}$ after injection then programmed at $2{ }^{\circ} \mathrm{C} / \mathrm{min}$ to $250{ }^{\circ} \mathrm{C}$, and maintained at 
that temperature for $45 \mathrm{~min}$. A solvent delay of $9 \mathrm{~min}$ was set before MS acquisition began. The transfer line from GC column to MS was set to $250{ }^{\circ} \mathrm{C}$, the source $230^{\circ} \mathrm{C}$, and the quadrupole $150^{\circ} \mathrm{C}$. MS detector was done by electron ionization at $70 \mathrm{eV}$, with a scan range of 41 a.m.u. to 450 a.m.u. (1 scan/s). Compounds were identified by using online NIST 05 and Wiley-7th library spectra, published MS data and analytical standards parameters of available compounds. Stock standard solutions of available aliphatic compounds, phenolic and tepenes were prepared by dissolving each compound in hexane separately at a concentration $0.5 \mathrm{mg} / \mathrm{mL}$. Decane was used as the internal standard and was dissolved in hexane at concentration $1.0 \mathrm{mg} / \mathrm{mL}$. Component relative percentages were calculated based on normalization method without using correction factors.

\subsection{Phenolic Compounds Analysis}

Reversed-phase high-performance liquid chromatography with diode array detection and electrospray ionization mass spectrometry (RP-HPLC-DAD-ESI-MS) procedure was used for phenolic compounds qualitative and quantitative analysis. Sample preparation for RP-HPLC-DAD-ESI-MS analysis: an accurately weighted, dried, and powdered D. palmatum herb samples $(200 \mathrm{mg})$ were placed in a conical flasks. Then $5 \mathrm{~mL}$ of $60 \%$ methanol were added and the mixtures were weighted. The samples were then extracted in an ultrasonic bath for $60 \mathrm{~min}$ at $45^{\circ} \mathrm{C}$ with an ultrasound power of $100 \mathrm{~W}$ and frequency of $35 \mathrm{kHz}$. After cooling, the flasks weights were reduced to initial sign, and the resultant extracts were filtered through a $0.22-\mu \mathrm{m}$ polytetrafluoroethylene (PTFE) syringe filter before injection into the HPLC system for analysis.

Experiments were performed on an LCMS 8050 liquid chromatograph coupled with diodearray-detector and triple-quadrupole electrospray ionization detector (Shimadzu, Columbia, MD, USA), using a GLC Mastro C18 column $(150 \times 2.1 \mathrm{~mm}, \varnothing 3 \mu \mathrm{m}$; Shimadzu, Kyoto, Japan); the column temperature was $30^{\circ} \mathrm{C}$. Eluent $\mathrm{A}$ was water and eluent $\mathrm{B}$ was acetonitrile. The injection volume was $1 \mu \mathrm{L}$, and elution flow was $200 \mu \mathrm{L} / \mathrm{min}$. Gradient program: $0-5 \mathrm{~min}, 5-18 \% \mathrm{~B} ; 5-12 \mathrm{~min}, 18-20 \% \mathrm{~B}$; $12-25 \mathrm{~min}, 20 \%$ B; $25-37 \mathrm{~min}, 20-45 \%$ B; 37-43 min, 45-70\% B; 43-58 min, 70-100\% B; and 58-60 min, $100-5 \%$ B. The DAD acquisitions were performed in the range of 200-600 $\mathrm{nm}$ and chromatograms were integrated at $280 \mathrm{~nm}$. For ESI-MS, the parameters were set as follows: temperature levels of ESI interface, desolvation line and heat block were $300^{\circ} \mathrm{C}, 250^{\circ} \mathrm{C}$ and $400{ }^{\circ} \mathrm{C}$, respectively; the flow levels of nebulizing gas $\left(\mathrm{N}_{2}\right)$, heating gas (air) and collision-induced dissociation gas (Ar) were $3 \mathrm{~L} / \mathrm{min}$, $10 \mathrm{~L} / \mathrm{min}$ and $0.3 \mathrm{~mL} / \mathrm{min}$, respectively. The capillary voltage was kept at $+4 \mathrm{kV}$ (simple phenols) in positive mode and at $-4.5 \mathrm{kV}$ (phenylpropanoids and flavonoids) in negative mode. ESI-MS spectra were recorded by scanning in the range of $m / z 100-1900$.

Quantification of phenolic compounds was realized in RP-HPLC-DAD experiments using chromatographic conditions mentioned above. To prepare the stock solutions of reference compounds, $1 \mathrm{mg}$ each of arbutin, 5-O-caffeoylquinic acid, 3-O-caffeoylquinic acid, caffeic acid, luteolin-7,4'-di-O-rutinoside (dracopalmaside), luteolin-7-O-rutinoside-4'-O-glucoside (cynarotriside), eriodictyol-7-O-rutinoside (eriocitrin), luteolin-7-O-rutinoside (scolymoside), eriodictyol-7-O-glucoside, luteolin-7-O-glucoside (cynaroside), luteolin-4'-O-glucoside, apigenin-7-O-rutinoside (isorhoifolin), naringenin-7-O-glucoside (prunin), apigenin-7-O-glucoside (cosmosiin), rosmarinic acid, eriodictyol, acacetin-7-O-rutinoside (linarin), acacetin-7-O-glucoside (tilianin), luteolin, naringenin, apigenin, chrysoeriol, acacetin, isothymusin, salvigenin, and genkwanin were accurately weighed and individually dissolved in DMSO/methanol mixture (1:4) in volumetric flasks $(1 \mathrm{~mL})$. The external standard calibration curve was generated using five data points, covering the concentration ranges $0.25-1.00 \mathrm{mg} / \mathrm{mL}$. The calibration curves were created by plotting the peak area vs. the concentration levels. Taxifolin $\left(t_{R} 32.54 \mathrm{~min}\right)$ and gardenin B ( $\left.t_{R} 48.63 \mathrm{~min}\right)$ were used as the internal standards and was dissolved separately in DMSO/methanol mixture $(1: 4)$ at concentration $1 \mathrm{mg} / \mathrm{mL}$. The concentrations of O-malonyl-arbutin, eriodictyol-O-malonyl-hexosides, apigenin-7-O-hexoside, luteolin-7-O-acetyl-hexoside and acacetin-7-O-acetyl-hexoside were calculated using arbutin, eriodictyol-7-O-glucoside, apigenin-7-O-glucoside, luteolin-7-O-glucoside and acacetin-7-O-glucoside, respectively, as reference 
compounds. The following correction coefficients were used to calculate contents of $O$-malonyl-arbutin, eriodictyol-O-malonyl-hexosides, luteolin-7-O-acetyl-hexoside and acacetin-7-O-acetyl-hexoside: 1.316, 1.191, 1.094 and 1.094, respectively. All analyses were carried out in triplicate and the data were expressed as mean value \pm standard deviation (SD).

\subsection{Carbohydrates Analysis}

\subsubsection{RP-HPLC-MS Analysis of Free Sugars}

RP-HPLC-DAD-ESI-MS procedure was used for analysis of free sugars. Sample preparation for free sugar analysis: an accurately weighted, dried, and powdered D. palmatum herb samples $(100 \mathrm{mg})$ were placed in a conical flasks. Then, $10 \mathrm{~mL}$ of $40 \%$ methanol were added and the mixtures were weighted. The samples were then extracted in an ultrasonic bath for $30 \mathrm{~min}$ at $50{ }^{\circ} \mathrm{C}$ with an ultrasound power of $100 \mathrm{~W}$ and frequency of $35 \mathrm{kHz}$. After cooling, the flasks weights were reduced to initial sign, and the resultant extracts were filtered through a $0.22-\mu \mathrm{m}$ polytetrafluoroethylene (PTFE) syringe filter before injection into the HPLC system for analysis.

Experiments were performed on an LCMS 8050 liquid chromatograph (Shimadzu, Columbia, $\mathrm{MD}, \mathrm{USA}$ ) coupled with diode-array-detector (DAD) and triple-quadrupole electrospray ionization detector (ESI), using a GLC Mastro C18 column $(150 \times 2.1 \mathrm{~mm}, \varnothing 3 \mu \mathrm{m}$; Shimadzu, Kyoto, Japan); the column temperature was $25^{\circ} \mathrm{C}$. Eluent $\mathrm{A}$ was water and eluent $\mathrm{B}$ was acetonitrile-water mixture (20:80). The injection volume was $1 \mu \mathrm{L}$, and elution flow was $150 \mu \mathrm{L} / \mathrm{min}$. Gradient program: 0-10 min, $2-8 \% \mathrm{~B}$; and $10-16 \mathrm{~min}, 8-12 \% \mathrm{~B}$. For selected ion monitoring mode (SIM) with negative ionization mass-spectrometry, the parameters were set as follows: SIM $m / z$ values-179 a.m.u. for glucose, 341 a.m.u. for sucrose, 503 a.m.u. for raffinose, 665 a.m.u. for stachyose; temperature levels of ESI interface, desolvation line and heat block were $300^{\circ} \mathrm{C}, 250^{\circ} \mathrm{C}$ and $400{ }^{\circ} \mathrm{C}$, respectively; the flow levels of nebulizing gas $\left(\mathrm{N}_{2}\right)$, heating gas (air) and collision-induced dissociation gas (Ar) were $3 \mathrm{~L} / \mathrm{min}$, $10 \mathrm{~L} / \mathrm{min}$ and $0.3 \mathrm{~mL} / \mathrm{min}$, respectively. The capillary voltage was kept at $-4 \mathrm{kV}$ in negative mode. RP-HPLC-MS quantification experiments were carried out at the same chromatographic conditions in SIM mode.

To prepare the stock solutions of reference sugars, $1 \mathrm{mg}$ of glucose, sucrose, raffinose and stachyose were accurately weighed and individually dissolved in water in volumetric flasks $(2 \mathrm{~mL})$. The external standard calibration curve was generated using five data points, covering the concentration range $0.1-0.5 \mathrm{mg} / \mathrm{mL}$. The calibration curves were created by plotting the peak area vs. the concentration levels. Quinic acid ( $\left.t_{R} 9.26 \mathrm{~min}\right)$ was used as the internal standard and was dissolved in water at concentration $0.4 \mathrm{mg} / \mathrm{mL}$. All the analyses were carried out in triplicate and the data were expressed as mean value \pm standard deviation (SD).

\subsubsection{Raw Water Soluble Polysaccharide (RWSP) Analysis}

Powdered dried D. palmatum herb (100 g) was extracted with $10 \mathrm{~L}$ of distilled water at $90{ }^{\circ} \mathrm{C}$ for $60 \mathrm{~min}$. The water extract was filtered to remove plant material, concentrated in vacuo to $200 \mathrm{~mL}$ and finally centrifuged at $3000 \mathrm{rpm}(20 \mathrm{~min})$. The resultant supernatant was precipitated with $95 \%$ ethanol (1:5) and centrifuged at $3000 \mathrm{rpm}(20 \mathrm{~min})$. The crude polysaccharide pellets were redissolved in water $(200 \mathrm{~mL})$ and treated by Sevag method three times to remove protein contaminants [93]. Deproteinised polysaccharide solution was intensively dialyzed against distilled water in dialysis tubes (MW-cut off $2 \mathrm{kDa}$; Sigma-Aldrich, St. Louis, MO, USA). Finally non-dialysed solution was passed though cation-exchange resin KU-2-8 ( $\mathrm{H}^{+}$-form, $200 \mathrm{~g}$; Closed Joint-Stock Company Tokem, Kemerovo, Russia) to remove mineral contaminants. The volume of the polysaccharide solution was reduced in vacuo $(200 \mathrm{~mL}$ ) and liophylized using freeze-dry apparatus Scientz Ordinary 10N (Ningbo Scientz Biotechnology Co., Ltd., Ningbo, China) to obtain off-white powder of RWSP.

Total carbohydrate content in RWSP was determined by a modified anthrone- $\mathrm{H}_{2} \mathrm{SO}_{4}$ spectrophotometric assay with glucose as a standard [94]. Estimation of uronic acid content was 
realized using 3,5-dimethylphenol- $\mathrm{H}_{2} \mathrm{SO}_{4}$ spectrophotometric assay with galacturonic acid as a standard [95]. To determine the protein concentration in RWSP the Bradford colorimetric method was used with BSA as a standard [96]. The tests of RWSP with iodine, resorcinol- $\mathrm{HCl}$ reagent, Yariv reagent and Fehling's reagent to qualify the presence of starch, inulin, arabinogalactan-protein complexes and mannans were performed as described previously [97-99].

The monosaccharide composition of RWSP was determined after acidic hydrolysis with trifluoroacetic acid (TFA) following by 1-phenyl-3-methyl-5-pyrazolone (PMP) labeling and microcolumn HPLC with ultraviolet detection separation (HPLC-UV) of PMP-labeled hydrolyzates. To hydrolyze RWSP samples $10 \mathrm{mg}$ was dissolved in $1 \mathrm{~mL}$ of $2 \mathrm{M}$ TFA in a $5 \mathrm{~mL}$ ampoule, incubated at $120{ }^{\circ} \mathrm{C}$ for $2 \mathrm{~h}$, the cooled reaction mixture was centrifuged at $2000 \mathrm{rpm}$ for $5 \mathrm{~min}$ and evaporated to dryness under reduced pressure to remove TFA, and the hydrolyzed and dried samples were redissolved in $1 \mathrm{~mL}$ of distilled water for the following experiments. PMP-labeling was performed using Sun et al. protocol [100] with slight modification. The hydrolyzed RWSP samples $(50 \mu \mathrm{L})$ were labeled by adding $15 \mu \mathrm{L}$ of $\mathrm{NaOH}(1.5 \mathrm{M})$ and $75 \mu \mathrm{L}$ of PMP solution $(0.5 \mathrm{M}$ in methanol). The mixtures were incubated at $70^{\circ} \mathrm{C}$ for $2 \mathrm{~h}$, cooled to room temperature, and neutralized with $60 \mu \mathrm{L}$ of $\mathrm{HCl}(0.5 \mathrm{M}), 1 \mathrm{~mL}$ of chloroform was added, and, after vigorous shaking $(20 \mathrm{~s})$ and centrifuging at $3000 \mathrm{rpm}$ for $10 \mathrm{~min}$, the organic phase was carefully removed and discarded. The aqueous layer was passed through a $0.45 \mu \mathrm{m}$ syringe filter before HPLC analysis.

Microcolumn HPLC-UV chromatographic separation of PMP-labeled sugars were achieved on an MiLiChrom A-02 microcolumn chromatograph (Econova; Novosibirsk, Russia) equipped with UV-detector. A microcolumn ProntoSIL-120-5-C18 AQ with a length of $75 \mathrm{~mm}$, inner diameter of $1 \mathrm{~mm}$, and particles diameter of $1 \mu \mathrm{m}$ was used for separation (Metrohm AG, Herisau, Switzerland). Separation was performed in a gradient mode with $100 \mathrm{mM} \mathrm{CH}_{3} \mathrm{COONH}_{4}$ solution $(\mathrm{pH}$ 6.9) as eluent $\mathrm{A}$, and acetonitrile as eluent $\mathrm{B}$ using the following gradient program: $0-20 \mathrm{~min}, 20-26 \% \mathrm{~B}$. The column temperature was $35^{\circ} \mathrm{C}$, injection volume was $1 \mu \mathrm{L}$, and elution was at $150 \mu \mathrm{L} / \mathrm{min}$. Chromatograms were recorded at $250 \mathrm{~nm}$. The retention times of PMP-labeled monosaccharides were followed: $6.94 \mathrm{~min}$ for mannose, $8.94 \mathrm{~min}$ for ribose, $9.15 \mathrm{~min}$ for rhamnose, $10.91 \mathrm{~min}$ for glucuronic acid, $11.38 \mathrm{~min}$ for galacturonic acid, $13.11 \mathrm{~min}$ for glucose, $13.73 \mathrm{~min}$ for galactose, $14.93 \mathrm{~min}$ for xylose, $15.11 \mathrm{~min}$ for arabinose, and $16.90 \mathrm{~min}$ for fucose.

To prepare the stock solutions of reference sugars, $1 \mathrm{mg}$ of mannose, ribose, rhamnose, glucose, galactose, xylose, arabinose, fucose, galacturonic acid and glucuronic acid were accurately weighed and individually dissolved in water in volumetric flasks $(2 \mathrm{~mL})$. All sugar reference samples were PMP-labeled before analysis. The external standard calibration curve was generated using five data points, covering the concentration range $0.01-0.05 \mathrm{mg} / \mathrm{mL}$. The calibration curves were created by plotting the peak area vs. the concentration levels. All the analyses were carried out in triplicate and the data were expressed as mean value \pm standard deviation (SD).

\subsection{Antioxidant Activity Assays}

Frozen leaves $(2 \mathrm{~g})$ were homogenized with $10 \mathrm{~mL}$ of $0.05 \mathrm{M}$ sodium phosphate buffer solution ( $\mathrm{pH} 7.8$ ) with $1 \%$ polyvivylpyrrolidone and was centrifuged at $12,000 \times \mathrm{g}$ at $4{ }^{\circ} \mathrm{C}$ for $15 \mathrm{~min}$. The supernatant was collected for malondialdehyde (MDA) and enzyme analysis. MDA content was measured using spectrophotometric assay based on the thiobarbituric acid reaction [101]. Superoxide dismutase activity was analyzed using spectrophotometric method of Giannopolitis-Ries with measurements of the inhibition levels of nitroblue tetrazolium reduction at $560 \mathrm{~nm}$ [102]. Catalase activity was measured using spectrophotometric method of Abassi et al. which include the measuring of $\mathrm{H}_{2} \mathrm{O}_{2}$ extinction decline at $240 \mathrm{~nm}$ [103].

The total antioxidant capacity of D. palmatum extracts was determined using the phosphomolybdic acid method [104]; the DPPH ${ }^{\bullet}$ radical scavenging activity and $\mathrm{ABTS}^{\bullet+}$ radical scavenging activity was assessed as described early [105]; the determination of superoxide anion scavenging activity $\left(\mathrm{O}_{2}{ }^{\bullet-}-\mathrm{SA}\right)$ was measured in phenazine methosulfate-nicotinamide adenine dinucleotide-nitroblue 
tetrazolium systems using the method of Ozen et al. [106]; the $\mathrm{Br}^{\bullet}$ radical scavenging activity (Br॰-SA) was determined using culometric method [105] with electrogenerated bromine radicals; the potential to inactivate $\mathrm{NO}$ was assessed by the sodium nitropusside technique [107]; the ability to inactivate $\mathrm{H}_{2} \mathrm{O}_{2}$ was determined using the technique developed by Badami and Channabasavaraj [108]; to evaluate the chelating activity for $\mathrm{Fe}^{2+}$ ions the $o$-phenanthroline technique was applied [59].

For preparation of the extract, accurately-weighed dried sample of D. palmatum herb (10 g) was transferred in a conical flask for preparation of the extracts. After that, $150 \mathrm{~mL}$ of solvent $(60 \%$ methanol solutions) was added with stirring and put in an ultrasonic bath. The extraction conditions were $60 \mathrm{~min}$ at $45^{\circ} \mathrm{C}$, ultrasound power of $100 \mathrm{~W}$, the frequency $35 \mathrm{kHz}$. The extraction was repeated twice. The obtained extract were filtered through a cellulose filter and combined. The filtrates were evaporated in vacuo until dryness with the use of a rotary evaporator.

\subsection{Statistical Analysis}

The results were given as the mean \pm standard deviation (SD). One-way analysis of variance (ANOVA) with a post hoc least significant difference test was used to determine significance $(p \leq 0.05)$ with Statistica 5.5 software (Dell Technologies Inc., Round Rock, TX, USA) together with the correlation matrix with the use of elementary statistics.

\section{Conclusions}

Since D. palmatum is a typical plant of arctic territory of Yakutia, it is a suitable model plant to qualify and quantify the plant physiological and biochemical responses to temperature change by lipophilic and hydrophilic compound formation and bioactivity variation. In the past, such studies have not been carried out using Yakutian plant as an experimental object. The present study demonstrated that long-term cultivation (20 days) of $D$. palmatum seedlings at low temperature $\left(1{ }^{\circ} \mathrm{C}\right)$ damaged plant organ integrity that affected on the rising level of electrolyte leakage and reactive oxygen species misbalance resulting in increasing concentration of malondialdehyde and antioxidant enzyme (superoxide dismutase and catalase). However, at the same time, accumulation of photosynthetic pigments, unsaturated fatty acids, EO and volatile monoterpenes; all groups of phenolic compounds including simple phenol derivatives, phenylpropanoids, flavone and flavanone derivatives; and soluble mono- and oligosaccharides and polysaccharides was observed in D. palmatum. All investigated antioxidant assays showed increased levels of bioactivity in the plant material collected at low temperature. For the first time, such multi-factor approach was used to research of D. palmatum and arctic plants as whole. While the relationship between temperature of plants cultivation and their chemical composition is complex, in the present study it was shown that the low temperature may cause specific chemical shifts achieving sustainable growth of the arctic plant. The scope and diverse of the information received allow to expand our knowledge about adaptive potential of arctic plants and their cold acclimation mechanisms. As far as the practical side is concerned, it is worth mentioning that the cold-induced accumulation of the various groups of compounds in D. palmatum confirmed the potential of low temperature cultivation for enrichment of arctic plants used in food and medicinal industries by bioactive components.

Acknowledgments: The authors acknowledge the financial support provided by the Ministry of Education and Science of Russia (Project No. 20.7216.2017/6.7), Project "Assessment, the main trends in change of the natural and socio-economic status, human development of the Arctic Economic Zone of the Republic of Sakha (Yakutia)" of the Program of Integrated Research in the Republic of Sakha (Yakutia) aimed at developing its productive forces and social sphere during 2016-2020, and FASO Russia (Project No. 0337-2016-0006).

Author Contributions: Daniil N. Olennikov and Nina I. Kashchenko designed the experiments; Tat'yana G. Gornostai and Inessa Yu. Selyutina performed the cultivation experiments; Nadezhda K. Chirikova and Nina I. Kashchenko performed the chemical and bioactivity experiments; Daniil N. Olennikov and Ifrat N. Zilfikarov analyzed the data; Daniil N. Olennikov and Nina I. Kashchenko wrote the paper.

Conflicts of Interest: The authors declare no conflict of interest. 


\section{References}

1. Ramakrishna, A.; Ravishankar, G.A. Influence of abiotic stress signals on secondary metabolites in plants. Plant Signal. Behav. 2011, 6, 1720-1731. [CrossRef] [PubMed]

2. Eremina, M.; Rozhon, W.; Poppenberger, B. Hormonal control of cold stress responses in plants. Cell. Mol. Life Sci. 2016, 73, 797-810. [CrossRef] [PubMed]

3. Guy, C.; Kaplan, F.; Kopka, J.; Selbig, J.; Hincha, D.K. Metabolomics of temperature stress. Physiol. Plant. 2008, 132, 220-235. [CrossRef] [PubMed]

4. Safronov, V.M. Climate change and mammals of Yakutia. Biol. Bull. 2016, 43, 1256-1270. [CrossRef]

5. Desyatkin, R.; Fedorov, A.; Desyatkin, A.; Konstantinov, P. Air temperature changes and their impact on permafrost ecosystems in Eastern Siberia. Therm. Sci. 2015, 19, S351-S360. [CrossRef]

6. Doron'kin, V.M.; Kovtonyuk, N.K.; Zuev, V.V. Flora of Siberia, 11; Nauka: Novosibirsk, Russia, 1997; pp. $170-185$.

7. Efremova, M.I.; Chirikova, N.K. Medicinal and Food Plants of Yakutia as Renewable Resources of Arctic; SVFU: Yakutsk, Russia, 2015; pp. 195-197.

8. Olennikov, D.N.; Chirikova, N.K.; Okhlopkova, Z.M.; Zulfugarov, I.S. Chemical composition and antioxidant activity of Tánara Ótó (Dracocephalum palmatum Stephan), a medicinal plant used by the North-Yakutian Nomads. Molecules 2013, 18, 14105-14121. [CrossRef] [PubMed]

9. Olennikov, D.N.; Chirikova, N.K. Dracopalmaside, a new flavonoid from Dracocephalum palmatum. Chem. Nat. Compd. 2015, 51, 1067-1069. [CrossRef]

10. Hussein, M.S.; El-Sherbeny, S.E.; Khalil, M.Y.; Naguib, N.Y.; Aly, S.M. Growth characters and chemical constituents of Dracocephalum moldavica L. plants in relation to compost fertilizer and planting distance. Sci. Hortic. 2006, 108, 322-331. [CrossRef]

11. Zeng, Q.; Jin, H.-Z.; Fu, J.-J.; Qin, J.-J.; Hu, X.-J.; Liu, J.-H.; Yan, L.; Chen, M.; Zhang, W.-D. Chemical constituents of plants from the genus Dracocephalum. Chem. Biodivers. 2010, 7, 1911-1929. [CrossRef] [PubMed]

12. Alaei, S.; Khosh-Khui, M.; Kobraee, S.; Zaji, B. Effect of different salinity levels on essential oil content and composition of Dracocephalum moldavica. Agric. Commun. 2014, 2, 42-46.

13. Said-Al Ahl, H.A.H.; Abdou, M.A.A. Impact of water stress and phosphorus fertilizer on fresh herb and essential oil content of dragonhead. Int. Agrophys. 2009, 23, 403-407.

14. Zhang, C.J.; Li, H.Y.; Yun, T.; Fu, Y.H.; Liu, C.M.; Gong, B.; Neng, B.J. Chemical composition, antimicrobial and antioxidant activities of the essential oil of Tibetan herbal medicine Dracocephalum heterophyllum Benth. Nat. Prod. Res. 2008, 22, 1-11. [CrossRef] [PubMed]

15. Alaei, S.; Mahna, N. Comparison of essential oil composition in Dracocephalum moldavica in greenhouse and field. J. Essent. Oil Bear. Plants 2013, 16, 346-351. [CrossRef]

16. Monsef-Esfahani, H.R.; Karamkhani, F.; Nickavar, B.; Abdi, K.; Faramarzi, M.A. The volatile constituents of Dracocephalum kotschyi oils. Chem. Nat. Compd. 2007, 43, 40-43. [CrossRef]

17. Murillo-Amador, B.; Morales-Prado, L.E.; Troyo-Diéguez, E.; Córdoba-Matson, M.V.; Hernández-Montiel, L.G.; Rueda-Puente, E.O.; Nieto-Garibay, A. Changing environmental conditions and applying organic fertilizers in Origanum vulgare L. Front. Plant Sci. 2015, 6, 549. [CrossRef] [PubMed]

18. Murillo-Amador, B.; Nieto-Garibay, A.; López-Aguilar, R.; Troyo-Diéguez, E.; Rueda-Puente, E.O.; Flores-Hernández, A.; Ruiz-Espinosa, F.H. Physiological, morphometric characteristics and yield of Origanum vulgare L. and Thymus vulgaris L. exposed to open-field and shade-enclosure. Ind. Crop. Prod. 2013, 49, 659-667. [CrossRef]

19. Georgieva, K.; Lichtenthaler, H.K. Photosynthetic response of different pea cultivars to low and high temperature treatments. Photosynthetica 2006, 44, 569-578. [CrossRef]

20. Glaszmann, J.C.; Kaw, R.N.; Khush, G.S. Genetic divergence among cold tolerant rices (Oryza satva L.). Euphytica 1990, 45, 95-104. [CrossRef]

21. Krol, M.; Huner, N.P.A.; McIntosh, A. Chloroplast biogenesis at cold hardening temperatures. Development of photosystem I and photosystem II activities in relation to pigment accumulation. Photosynth. Res. 1988, 14, 97-112. [CrossRef] [PubMed]

22. Goli, S.A.H.; Sahafi, S.M.; Rashidi, B.; Rahimmalek, M. Novel oilseed of Dracocephalum kotschyi with high n-3 to n-6 polyunsaturated fatty acid ratio. Ind. Crop. Prod. 2013, 43, 188-193. [CrossRef]

23. Domokos, J.; Peredi, J.; Halasz-Zelnik, K. Characterization of seed oils of dragonhead (Dracocephalum moldavica L.) and catnip (Nepeta cataria var. citriodora Balb.). Ind. Crop. Prod. 1994, 3, 91-94. [CrossRef] 
24. Marin, P.D.; Sajdl, V.; Kapor, S.; Tatic, B.; Petkovic, B. Fatty acids of the Saturejoideae, Ajugoideae and Scutellarioideae (Lamiaceae). Phytochemistry 1991, 30, 2979-2982. [CrossRef]

25. Tulucku, E. Herbal tea fatty acid content of some medicinal plants grown in Konya, Turkey. Asian J. Chem. 2011, 23, 1369-1379.

26. Ahmad, P. Oilseed Crops: Yield and Adaptations under Environmental Stress; John Wiley \& Sons Ltd.: Chichester, UK, 2017; pp. 80-91.

27. Schulte, L.R.; Ballard, T.; Samarakoon, T.; Yao, L.; Vadlani, P.; Staggenborg, S.; Rezac, M. Increased growing temperature reduces content of polyunsaturated fatty acids in four oilseed crops. Ind. Crop. Prod. 2013, 51, 212-219. [CrossRef]

28. Tajabadi, F.; Khalighi-Sigaroodi, F.; Rezazadech, S. Improving gas chromatography-mass spectrometry analysis of essential oils by multivariate curve resolution: Full identification of co-eluting compounds of Dracocephalum moldavica L. Chromatographia 2017, 80, 1069-1077. [CrossRef]

29. Nezhadali, A.; Khazaeifar, A.; Akbarpour, M.; Masrournia, M. Chemical composition of essential oil and antibacterial activity of Dracocephalum subcapitatum. J. Essent. Oil Bear. Plants 2010, 13, 112-117. [CrossRef]

30. Sonboli, A.; Esmaeili, M.A.; Gholipour, A.; Kanani, M.R. Composition, cytotoxicity and antioxidant activity of the essential oil of Dracocephalum surmandinum from Iran. Nat. Prod. Commun. 2010, 5, 341-344. [PubMed]

31. Esmaeli, M.A.; Sonboli, A.; Mirjalili, M.H. Oxidative stress protective effect of Dracocephalum multicaule essential oil against human cancer cell line. Nat. Prod. Res. 2014, 28, 848-852. [CrossRef] [PubMed]

32. Sonboli, A.; Gholipour, A.; Yousefzadi, M. Antibacterial activity of the essential oil and main components of two Dracocephalum species from Iran. Nat. Prod. Res. 2012, 26, 2121-2125. [CrossRef] [PubMed]

33. Lee, S.B.; Cha, K.H.; Kim, S.N.; Altantsetseg, S.; Shatar, S.; Sarangerel, O.; Nho, C.W. The antimicrobial activity of essential oil from Dracocephalum foetidum against pathogenic microorganisms. J. Microbiol. 2007, 45, 53-57. [PubMed]

34. Mahmood, U.; Kaul, V.K.; Singh, V.; Brij, L.; Negi, H.R.; Ahuja, P.S. Volatile constituents of the cold desert plant Dracocephalum heterophyllum Benth. Flavour Fragr. J. 2005, 20, 173-175. [CrossRef]

35. Suleimen, E.M.; Myrzagalieva, A.B.; Ibataev, Z.A.; Iskakova, Z.B.; Samarkhanov, T.N.; Medeubaeva, B.Z. Constituent composition and biological activity of essential oil from Dracocephalum peregrinum. Chem. Nat. Compd. 2017, 53, 173-174. [CrossRef]

36. Sadraei, H.; Asghari, G.; Kasiri, F. Comparison of antispasmodic effects of Dracocephalum kotschyi essential oil, limonene and $\alpha$-terpineol. Res. Pharm. Sci. 2015, 10, 109-116. [PubMed]

37. Ahmadi, L.; Mirza, M. Volatile constituents of Dracocephalum aucherry Boiss. J. Essent. Oil Res. 2001, 13, 202-203. [CrossRef]

38. Agarwal, S.G.; Kapahi, B.K.; Thappa, R.K. Essential oil constituents of Himalayan Dracocephalum speciosum Benth. J. Essent. Oil Res. 2005, 17, 94-95. [CrossRef]

39. Sangwan, N.S.A.; Farooqi, H.A.; Shabih, F.; Sangwan, R.S. Regulation of essential oil production in plants. Plant Growth Regul. 2001, 34, 3-21. [CrossRef]

40. Prakasa Rao, E.V.S.; Rao, R.S.G.; Ramesh, S. Seasonal variation in oil content and its composition in two chemotypes of scented geranium (Pelaronium spp.). J. Essent. Oil Res. 1995, 7, 159-163. [CrossRef]

41. Putievsky, E.; Ravid, U.; Dudai, N. The influence of season and harvest frequency on essential oil and herbal yields from a pure clone of sage grown under cultivated conditions. J. Nat. Prod. 1986, 49, 326-329. [CrossRef]

42. Burbott, A.J.; Loomis, W.D. Effects of light and temperature on the monoterpenes of peppermint. Plant Physiol. 1967, 42, 20-28. [CrossRef] [PubMed]

43. Clark, R.J.; Menary, R.C. Environmental effects on peppermint (M. piperita L.) effect of day length, photon flux density, night and day temperature on yield and composition of peppermint oil. Aust. J. Plant Physiol. 1980, 7, 685-692. [CrossRef]

44. Qiao, J.Q.; Xu, D.; Lian, H.Z.; Ge, X. Analysis of related substances in synthetical arbutin and its intermediates by HPLC-UV and LC-ESI-MS. Res. Chem. Intermed. 2015, 41, 691-703. [CrossRef]

45. Martínez-Vázquez, M.; Estrada-Reyes, R.; Martínez-Laurrabaquio, A.; López-Rubalcava, C.; Heinze, G. Neuropharmacological study of Dracocephalum moldavica L. (Lamiaceae) in mice: Sedative effect and chemical analysis of an aqueous extract. J. Ethnopharmacol. 2012, 141, 908-917. [CrossRef] [PubMed]

46. Lukas, B.; Schmiderer, C.; Mitteregger, U.; Novak, J. Arbutin in marjoram and oregano. Food Chem. 2010, 121, 185-190. [CrossRef] 
47. Valant-Vetschera, K.M.; Roitman, J.N.; Wollenweber, E. Chemodiversity of exudate flavonoids in some members of the Lamiaceae. Biochem. Syst. Ecol. 2003, 31, 1279-1289. [CrossRef]

48. Selenge, E.; Murata, T.; Tanaka, S.; Sasaki, K.; Batkhuu, J.; Yoshizaki, F. Monoterpene glycosides, phenylpropanoids, and acacetin glycosides from Dracocephalum foetidum. Phytochemistry 2014, 101, 91-100. [CrossRef] [PubMed]

49. Dai, L.-M.; Zhao, C.-C.; Jin, H.-Z.; Tang, J.; Shen, Y.-H.; Li, H.-L.; Peng, C.-Y.; Zhang, W.-D. A new ferulic acid ester and other constituents from Dracocephalum peregrinum. Arch. Pharm. Res. 2008, 31, 1325-1329. [CrossRef] [PubMed]

50. Fu, P.; Zhao, C.-C.; Tang, J.; Shen, Y.-H.; Xu, X.-K.; Zhang, W.-D. New flavonoid glycosides and cyanogenic glycosides from Dracocephalum peregrinum. Chem. Pharm. Bull. 2009, 57, 207-210. [CrossRef] [PubMed]

51. She, G.; Guo, Z.; Lv, H.; She, D. New flavonoid glycosides from Elsholtzia rugulosa Hemsl. Molecules 2009, 14, 4190-4196. [CrossRef] [PubMed]

52. Lee, J.Y.; Chang, E.J.; Kim, H.J.; Park, J.H.; Choi, S.W. Antioxidative flavonoids from leaves of Carthamus tinctorius. Arch. Pharm. Res. 2002, 25, 313-319. [CrossRef] [PubMed]

53. Abad-García, B.; Garmón-Lobato, S.; Berrueta, L.A.; Gallo, B.; Vicente, F. On line characterization of 58 phenolic compounds in Citrus fruit juices from Spanish cultivars by high-performance liquid chromatography with photodiode-array detection coupled to electrospray ionization triple quadrupole mass spectrometry. Talanta 2012, 99, 213-224. [CrossRef] [PubMed]

54. Abad-García, B.; Berrueta, L.A.; Garmón-Lobato, S.; Gallo, B.; Vicente, F. A general analytical strategy for the characterization of phenolic compounds in fruit juices by high-performance liquid chromatography with diode array detection coupled to electrospray ionization and triple quadrupole mass spectrometry. J. Chromatogr. A 2009, 1216, 5398-5415. [CrossRef] [PubMed]

55. Olennikov, D.N.; Akobirshoeva, A.A. Flavonoids and phenylpropanoids of Nepeta glutinosa and Ziziphora pamiroalaica. Chem. Nat. Compd. 2016, 52, 909-912. [CrossRef]

56. Fattahi, M.; Nazeri, V.; Torras-Claveria, L.; Sefidkon, F.; Cusido, R.M.; Zamani, Z.; Palazon, J. Identification and quantification of leaf surface flavonoids in wild-growing populations of Dracocephalum kotschyi by LC-DAD-ESI-MS. Food Chem. 2013, 141, 139-146. [CrossRef] [PubMed]

57. Neugart, S.; Kläring, H.-P.; Zietz, M.; Schreiner, M.; Rohn, S. The effect of temperature and radiation on flavonol aglycones and flavonol glycosides of kale (Brassica oleracea var. sabelica). Food Chem. 2012, 133, 1456-1465. [CrossRef]

58. Klimov, S.V.; Burakhanova, E.A.; Dubinina, I.M.; Alieva, G.P.; Sal'nikova, E.B.; Olenichenko, N.A.; Zagoskina, N.V.; Trunova, T.I. Suppression of the source activity affects carbon distribution and frost hardiness of vegetating winter wheat plants. Russ. J. Plant Physiol. 2008, 55, 308-314. [CrossRef]

59. Olennikov, D.N.; Kashchenko, N.I.; Chirikova, N.K. A novel HPLC-assisted method for investigation of the $\mathrm{Fe}^{2+}$-chelating activity of flavonoids and plant extracts. Molecules 2014, 19, 18296-18316. [CrossRef] [PubMed]

60. Moheb, A.; Ibrahim, R.K.; Roy, R.; Sarhan, F. Changes in wheat leaf phenolome in response to cold acclimation. Phytochemistry 2011, 72, 2294-2307. [CrossRef] [PubMed]

61. Mierziak, J.; Kostyn, K.; Kulma, A. Flavonoids as important molecules of plant interactions with the environment. Molecules 2014, 19, 16240-16265. [CrossRef] [PubMed]

62. Tomás-Barberán, F.A.; Husain, S.Z.; Gil, M.I. The distribution of methylated flavones in the Lamiaceae. Biochem. Syst. Ecol. 1988, 16, 43-46. [CrossRef]

63. Tomás-Barberán, F.A.; Wollenweber, E. Flavonoid aglycones of the leaf surfaces of some Labiatae species. Plant Syst. Evol. 1990, 173, 109-118. [CrossRef]

64. Amid, A.; Lytovchenko, A.; Fernie, A.R.; Warren, G.; Thorlby, G.J. The sensitive to freezing3 mutation of Arabidopsis thaliana is a cold-sensitive allele of homomeric acetyl-CoA carboxylase that results in cold-induced cuticle deficiencies. J. Exp. Bot. 2012, 14, 5289-5299. [CrossRef] [PubMed]

65. Yeats, T.H.; Rose, J.K.C. The formation and function of plant cuticles. Plant Physiol. 2013, 163, 5-20. [CrossRef] [PubMed]

66. Pfündel, E.E.; Agati, G.; Cerovic, Z.G. Optical properties of plant surfaces. In Biology of the Plant Cuticle; Riederer, M., Müller, C., Eds.; Blackwell: Oxford, UK, 2006.

67. Theocharis, A.; Clément, C.; Barka, E.A. Physiological and molecular changes in plants grown at low temperatures. Planta 2012, 235, 1091-1105. [CrossRef] [PubMed] 
68. Dos Santos, R.; Vergauwen, R.; Pacolet, P.; Lescrinier, E.; van den Ende, W. Manninotriose is a major carbohydrate in red deadnettle (Lamium purpureum, Lamiaceae). Ann. Bot. 2013, 111, 385-393. [CrossRef] [PubMed]

69. Bohnert, H.J.; Sheveleva, E. Plant stress adaptations-Making metabolism move. Curr. Opin. Plant Biol. 1998, 1, 267-274. [CrossRef]

70. Jouve, L.; Hoffmann, L.; Hausman, J.F. Polyamine, carbohydrate, and proline content changes during salt stress exposure of aspen (Populus tremula L.): Involvement of oxidation and osmoregulation metabolism. Plant Biol. 2004, 6, 74-80. [CrossRef] [PubMed]

71. Van den Ende, W. Multifunctional fructans and raffinose family oligosaccharides. Front. Plant Sci. 2013,4 , 247. [CrossRef] [PubMed]

72. Le Gall, H.; Philippe, F.; Domon, J.M.; Gillet, F.; Pelloux, J.; Rayon, C. Cell wall metabolism in response to abiotic stress. Plants 2015, 16, 112-166. [CrossRef] [PubMed]

73. Pollock, C.J.; Lloyd, E.J. The effect of low temperature upon starch, sucrose and fructan synthesis in leaves. Ann. Bot. 1987, 60, 231-235. [CrossRef]

74. Yano, R.; Nakamura, M.; Yoneyama, T.; Nishid, I. Starch-related $\alpha$-glucan/water dikinase is involved in the cold-induced development of freezing tolerance in Arabidopsis. Plant Physiol. 2005, 138, 837-846. [CrossRef] [PubMed]

75. Solecka, D.; Zebrowski, J.; Kacperska, A. Are involved in cold acclimation and de-acclimation of winter oil-seed rape plants? Ann. Bot. 2008, 101, 521-530. [CrossRef] [PubMed]

76. Baldwin, L.; Domon, J.M.; Klimek, J.F.; Fournet, F.; Sellier, H.; Gillet, F.; Pelloux, J.; Lejeune-Hénaut, I.; Carpita, N.C.; Rayon, C. Structural alteration of cell wall pectins accompanies pea development in response to cold. Phytochemistry 2014, 104, 37-47. [CrossRef] [PubMed]

77. Zhang, Q.; Chen, Q.; Wang, S.; Hong, Y.; Wang, Z. Rice and cold stress: Methods for its evaluation and summary of cold tolerance-related quantitative trait loci. Rice 2014, 7, 24. [CrossRef] [PubMed]

78. Fan, J.; Ren, J.; Zhu, W.; Amombo, E.; Fu, J.; Chen, L. Antioxidant responses and gene expression in bermudagrass under cold stress. J. Am. Soc. Hortic. Sci. 2014, 139, 699-705.

79. Soydam, A.S.; Büyük, I.; Aras, S. Relationships among lipid peroxidation, SOD enzyme activity, and SOD gene expression profile in Lycopersicum esculentum L. exposed to cold stress. Genet. Mol. Res. 2013, 12, 3220-3229. [CrossRef] [PubMed]

80. Camejo, D.; Martí Mdel, C.; Nicolás, E.; Alarcón, J.J.; Jiménez, A.; Sevilla, F. Response of superoxide dismutase isoenzymes in tomato plants (Lycopersicon esculentum) during thermo-acclimation of the photosynthetic apparatus. Physiol. Plant. 2007, 131, 367-377. [CrossRef] [PubMed]

81. Esimi, N.; Atici, Ö. Relationships between some endogenous signal compounds and the antioxidant system in response to chilling stress in maize (Zea mays L.) seedlings. Turk. J. Bot. 2016, 40, 37-44. [CrossRef]

82. Brown, J.E.; Rice-Evans, C.A. Luteolin-rich artichoke extract protects low density lipoprotein from oxidation in vitro. Free Radic. Res. 1998, 29, 247-255. [CrossRef] [PubMed]

83. Aprotosoaie, A.C.; Mihai, C.T.; Vochita, G.; Rotinberg, P.; Trifan, A.; Luca, S.V.; Petreus, T.; Gille, E.; Miron, A. Antigenotoxic and antioxidant activities of a polyphenolic extract from European Dracocephalum moldavica $\mathrm{L}$. Ind. Crop. Prod. 2016, 79, 248-257. [CrossRef]

84. Wang, S.-Q.; Han, X.-Z.; Li, X.; Ren, D.-M.; Wang, X.-N.; Lou, H.-X. Flavonoids from Dracocephalum tanguticum and their cardioprotective effects against doxorubicin-induced toxicity in H9c2 cells. Bioorg. Med. Chem. Lett. 2010, 20, 6411-6415. [CrossRef] [PubMed]

85. Raj, X.J.; Chaurasia, O.P.; Vajpayee, P.K.; Murugan, M.P.; Bala, S.S. Antioxidative activity and phytochemical investigation on a high altitude medicinal plant Dracocephalum heterophyllum Benth. Pharmacogn. J. 2010, 2, 112-117.

86. Sharifi, B.; Goli, S.A.H.; Maghsoudlou, Y. Antioxidant activity and chemical composition of the methanolic extract and related fractions of Dracocephalum kotschyi leaves using liquid chromatography-tandem mass spectrometry. Ind. Crop. Prod. 2017, 104, 111-119. [CrossRef]

87. Pouraboli, I.; Nazari, S.; Sabet, N.; Sharififar, F.; Jafari, M. Antidiabetic, antioxidant, and antilipid peroxidative activities of Dracocephalum polychaetum shoot extract in streptozotocin-induced diabetic rats: In vivo and in vitro studies. Pharm. Biol. 2016, 54, 272-278. [CrossRef] [PubMed]

88. Campos, P.S.; Quartin, V.; Ramalh, J.C.; Nunes, M.A. Electrolyte leakage and lipid degradation account for cold sensitivity in leaves of Coffea sp. plants. J. Plant Physiol. 2003, 160, 283-292. [CrossRef] [PubMed] 
89. Lichtenthaler, H.K.; Buschmann, C. Chlorophylls and Carotenoids: Measurement and Characterization by UV-VIS Spectroscopy. In Current Protocols in Food Analytical Chemistry; Unit F4.3.1-Unit F4.3.8; John Wiley \& Sons: Weinheim, Germany, 2010.

90. Vernon, L.P. Spectrophotometric determination of chlorophylls and pheophytins in plant extracts. Anal. Chem. 1960, 32, 1144-1150. [CrossRef]

91. Olennikov, D.N.; Agafonova, S.V.; Penzina, T.A.; Borovskii, G.B. Fatty acid composition of fourteen wood-decaying basidiomycete species growing in permafrost conditions. Rec. Nat. Prod. 2014, 8, 184-188.

92. Pedneault, K.; Angers, P.; Avis, T.J.; Gosselin, A.; Tweddell, R.J. Fatty acids profiles of polar and non-polar lipids of Pleurotus ostreatus and P. cornucopiae var. 'citrino-pileatus' grown at different temperatures. Mycol. Res. 2007, 111, 1228-1234. [CrossRef] [PubMed]

93. Sevag, M.G.; Lackman, D.B.; Smolens, J. The isolation of the components of Streptococcal nucleoproteins in serologically active form. J. Biol. Chem. 1938, 124, 425-436.

94. Olennikov, D.N.; Tankhaeva, L.M.; Samuelsen, A.B. Quantitative analysis of polysaccharides from Plantago major using the Dreywood method. Chem. Nat. Compd. 2006, 42, 265-268. [CrossRef]

95. Usov, A.T.; Bilan, M.I.; Klochkova, N.G. Polysaccharides of algae. 48. Polysaccharide composition of several calcareous red algae: Isolation of alginate from Corallina pilulitara P. et R. (Rhodophyta, Corallinaceae). Bot. Mar. 1995, 35, 43-51. [CrossRef]

96. Bradford, M.M. A rapid and sensitive method for the quantification of microgram quantities of protein utilizing the principle of protein-dye binding. Anal. Biochem. 1976, 76, 248-254. [CrossRef]

97. Olennikov, D.N.; Stolbikova, A.V.; Rokhin, A.V.; Khobrakova, V.B.; Tankhaeva, L.M. Polysaccharides from Fabaceae. V. $\alpha$-Glucan from Sophora flavescens roots. Chem. Nat. Compd. 2011, 47, 1-6. [CrossRef]

98. Olennikov, D.N.; Tankhaeva, L.M. A quantitative assay for total fructans in burdock (Arctium spp.) roots. Russ. J. Bioorg. Chem. 2011, 37, 893-898. [CrossRef]

99. Togola, A.; Inngjerdingen, M.; Diallo, D.; Barsett, H.; Rolstad, B. Polysaccharides with complement fixing and macrophage stimulation activity from Opilia celtidifolia, isolation and partial characterization. J. Ethnopharmacol. 2007, 115, 423-431. [CrossRef] [PubMed]

100. Sun, Z.; Song, C.; Xia, L.; Wang, X.; Suo, Y.; You, J. Comprehensive comparisons between 1-phenyl-3methyl-5-pyrazolones, 1-(4-methoxyphenyl)-3-methyl-5-pyrazolones and 1-(2-naphthyl)-3-methyl-5pyrazolones as labeling reagents used in LC-DAD-ESI-MS-MS analysis of neutral aldoses and uronic acids. Chromatographia 2010, 71, 789-797. [CrossRef]

101. Chen, J.W.; Cao, K.F. Changes in activities of antioxidative system and monoterpene and photochemical efficiency during seasonal leaf senescence in Hevea brasiliensis trees. Acta Physiol. Plant. 2008, 30, 1-9. [CrossRef]

102. Giannopolitis, C.N.; Ries, S.K. Superoxide dismutases: I. Occurrence in higher plants. Plant Physiol. 1977, 59, 309-314. [CrossRef] [PubMed]

103. Abassi, N.A.; Kushad, M.M.; Endress, A.G. Active oxygen-scavenging enzymes activities in developing apple flowers and fruits. Sci. Hortic. 1998, 74, 183-184. [CrossRef]

104. Preito, P.; Pineda, M.; Aguilar, M. Spectrophotometric quantitation of antioxidant capacity through the formation of a phosphomolybdenum complex: Specific application to the determination of vitamin E. Anal. Biochem. 1999, 269, 337-341. [CrossRef] [PubMed]

105. Olennikov, D.N.; Kashchenko, N.I.; Chirikova, N.K. Meadowsweet teas as new functional beverages: Comparative analysis of nutrients, phytochemicals and biological effects of four Filipendula species. Molecules 2017, 27, 16. [CrossRef] [PubMed]

106. Ozen, T.; Demirtas, I.; Aksit, H. Determination of antioxidant activities of various extracts and essential oil compositions of Thymus praecox subsp. skorpilii var. skorpilii. Food Chem. 2011, 124, 58-64. [CrossRef]

107. Kumar, S.; Kumar, D.; Jusha, M.; Saroha, K.; Singif, N.; Vashishta, B. Antioxidant and free radical scavenging potential of Citrullus colocynthis (L.) Schrad. methanolic fruit extract. Acta Pharm. 2008, 58, 215-220. [CrossRef] [PubMed]

108. Badami, S.; Channabasavaraj, K.P. In vitro antioxidant activity of thirteen medicinal plants of India's Western Ghats. Pharm. Biol. 2007, 45, 392-396. [CrossRef]

(C) 2017 by the authors. Licensee MDPI, Basel, Switzerland. This article is an open access article distributed under the terms and conditions of the Creative Commons Attribution (CC BY) license (http://creativecommons.org/licenses/by/4.0/). 